Mohamed Mahmoud Ismail, Predictive maintenance based on earlier fault detection on multi phase induction machines using neural network artificial intelligent techniques, pp. 1612 - 1636

\title{
PREDICTIVE MAINTENANCE BASED ON EARLIER FAULT DETECTION OF MULTI PHASE INDUCTION MACHINES USING NEURAL NETWORK ARTIFICIAL INTELLIGENT TECHNIQUES
}

\author{
Mohamed Mahmoud Ismail \\ Electrical Power and Machine Department, Faculty of Engineering Helwan University
}

Received 11 December 2012, accepted 25 May 2013

\begin{abstract}
The area of multiphase variable-speed motor drives in general and multiphase induction Motor drives in particular have experienced a substantial growth since the beginning of this century. Research has been conducted worldwide and numerous interesting developments have been reported in the literature. An attempt is made to provide a detailed overview of the current state-ofthe-art in this area. The elaborated aspects include advantages of multiphase induction machines, modeling of multiphase induction machines. This paper also provides a detailed survey of the control strategies for five-phase and asymmetrical six-phase induction motor drives for the saturated model of the induction motor. However all the old researches in this field are obtained using the approximate linear model of the induction machine which is not exactly accurate because that we are not guarantee that the motor operation is not in the saturation region. These results are also included for clarifying the behavior of the five and six phase using the saturated model of induction machine as an examples of the multi phase machine.

Also this paper presents an approach to induction motor fault diagnosis and condition prognosis based on neural network and adaptive neuro-fuzzy inference systems (ANFIS). The ANFIS is a neural network structured upon fuzzy logic principles, which enables the neural fuzzy system to provide the motor condition and fault detection process. This knowledge is provided by the fuzzy parameters of member ship functions and fuzzy rules. By using the neural network and (ANFIS) techniques, we can detect and locate the inter-turn short circuit fault in the stator winding of an induction motor. Simulation results are presented to demonstrate the effectiveness of the proposed method.
\end{abstract}

Keywords: Induction motor, Fault detection, Neural network, ANFIS

\section{Introduction}

In the last decade, a tremendous development in the theory of nonlinear control has been achieved. This achievement was via applying differential geometric approaches to control problems. Because of the challenging control problem posed by induction motors, several feedback linearization based solutions were proposed. It is, by now, well known that the induction motor model with a linear magnetic circuit is not feedback linearizable by static feedback. However input-output linearization and decoupling can be achieved in the (d, q) frame [1] and in the (a, b) frame [2] by static feedback. Furthermore, exact linearization is possible by simplifying the model and treating the speed as a time varying parameter by dynamic compensation as in [3] and by static state feedback as in [4]. Also, I: \also exact linearization can be realized for the full model by dynamic feedback [5]. An adaptive version of [2] can be found in [6], where asymptotic tracking of the true values of the load

Corresponding author.

E-mail:m_m_ismail@yahoo.com 
1613

Mohamed Mahmoud Ismail, Predictive maintenance based on earlier fault detection on multi phase induction machines using neural network artificial intelligent techniques, pp. 1612 - 1636

torque and rotor resistance are obtained assuming they are constant or slowly varying but unknown. The main drawback in [6] is the requirement of flux measurements, which was removed in [7]. A further improvement of [7], is presented in [8], where the requirement of speed measurement is removed. An adaptive improvement of [4] is given in [9]. In [10], it is shown that the approach of [5], presented in the $(a, b)$ frame is greatly simplified by considering the model in the $(\mathrm{d}, \mathrm{q})$ frame. The common assumption made in the development of these control laws is the linearity of the magnetic circuit of the machine. This assumption is usually justified by including the flux magnitude in the outputs to be regulated by the controller and keeping this magnitude regulated at a value far from the saturation region [6]. However there are no guarantees that the flux magnitude remains in the linear magnetic region during machine transients. Moreover in many variable torque applications, it is desirable to operate the machine in the magnetic saturation region to allow the machine to develop higher torque as illustrated in [11-12]. Saturation effects are also known to be pronounced in drives operating in the field weakening region, or in drives that operate with varying flux levels to achieve optimally in a specified sense [13]. However, the operation of the motor at various magnetization levels makes the nominal inductance a bad approximation. Recently, researchers have been attracted to induction motor control with magnetic saturation. Feedback input-output linearization schemes for induction motors with magnetic saturation were proposed in a fixed stator frame [14] and in a synchronously rotating frame [15]. While in [14] the control signal is the stator voltage, in [15] it is the stator current. Both papers treat the T-model of an induction motor. Unfortunately, due to the complicated nature of the T-model, drastic simplifications are required to facilitate the use of this model in nonlinear control synthesis. The major drawback in [14] (also present in the optimal flux reference selection of [15]) is the assumption that the stator and rotor leakage parameters os and or, as defined in [16], are equal and constant. This assumption has the indirect effect of neglecting any crosssaturation effect that might appear in the dynamics of the motor. On the other hand, the model in [15] is obtained by firstly simplifying the motor equations assuming a linear magnetic circuit and then including a mutual inductance that varies with mutual current. This approach does not include derivatives of the saturation function that should appear in a complete model [17]. A similar modeling approach can also be found in [18] for incorporating magnetic saturation in the passivity-based control design methodology of [19]. It is worth pointing out that, in [18] similar to [15], stator currents are used as the control signal. All the work presented so far is based on a T-model of the induction motor, contrary to the $\pi$-model proposed in [11]. The $\pi$-model differs from the conventional $\mathrm{T}$ model in that it is more closely related to the physical structure of the machine, since its derivation is primarily based on the stator-rotor tooth pair magnetic circuit. Even though the work in [11] is based on a wound rotor motor, it is shown in the same paper how the modeling approach can be applied to a squirrel cage motor. It is not difficult to show that both models are equivalent when a linear magnetic circuit is assumed, this equivalence does not hold when main flux saturation is included. In the published work [20], It was shown that considering magnetic saturation explicitly in nonlinear control synthesis is of foremost importance especially when the machine is voltage actuated. Because the $\pi$ -

Journal of Engineering Sciences, Assiut University, Faculty of Engineering, Vol. 41, No. 4, July, 2013,E-mail address: jes@aun.edu.eg 
Mohamed Mahmoud Ismail, Predictive maintenance based on earlier fault detection on multi phase induction machines using neural network artificial intelligent techniques, pp. 1612 - 1636

model was experimentally found in [11] to be better suited to capture the nonlinear magnetic effects.

Many techniques are performed for detection of the motor faults [21-38]. The previous procedure are deal with the linear model of the induction motor and deal with the online diagnostics of the motor fault detection, from the previous work we find that many factors are lead to motor faults such that bearing faults induce $40 \%$ of the motor faults , $38 \%$ are due to the stator winding, $10 \%$ are due to rotor faults and $12 \%$ other faults .

This paper is aimed to developing a mathematical model of multi phase induction motor taking the saturation in consideration.

\section{Characteristics of multiphase induction motors}

As all students of electrical engineering are aware, three phase induction motors will accelerate their loads from rest and will run without producing a twice line-frequency pulsating torque. Machines having more than three phases exhibit the same properties, but those with one or two phases do not. This was one of the clinching arguments that led to the universal adoption of three phases for electrical power systems, more than a century ago. However, increasing numbers of induction motors are not connected directly to threephase supplies. Instead, they derive their excitation from a power electronic converter, the input stage of which is connected to a three-phase supply. The output stage of the converter and the stator winding of the motor must have the same number of phases, but provided this simple requirement is met, any number of phases may be used. There is still the common choice, however, not only for the reasons given above, but also because the mass production of three-phase motors for main excitation keeps their unit cost low and standardization enables motors to be sourced from any manufacturer. Despite the above, there has been an upsurge of interest in multiphase machines, that is machines with more than three phases. There are several reasons for this, the principal ones being:

(1). the stator excitation in a multiphase machine produces a field with a lower spaceharmonic content, so that the efficiency is higher than in a three-phase machine.

(2).Multiphase machines have a greater fault tolerance than their three-phase counterparts. If one phase of a three-phase machine becomes open-circuited the machine becomes single-phase. It may continue to run but requires some external means for starting, and must be massively de-rated. If one phase of a 15-phase machine becomes open circuited, it will still self-start and will run with only minimal de-rating.

(3).Multiphase machines are less susceptible than their three-phase counterparts to timeharmonic components in the excitation waveform. Such excitation components produce pulsating torques at even multiples of the fundamental excitation frequency.

It is to be noted that another important reason for employing multiphase motor variablespeed drives is the possibility of reducing the required rating of power electronic components for the given motor output power, when compared to a three-phase motor drive, an aspect that becomes of huge significance in high power drives, such as those aimed at electric ship propulsion . Utilization of multiphase motor drives also enables improvement in the noise characteristics, when compared to three-phase motor drives, this being a consequence of the properties listed above.

Journal of Engineering Sciences, Assiut University, Faculty of Engineering, Vol. 41, No. 4, July, 2013,E-mail address: jes@aun.edu.eg 
Mohamed Mahmoud Ismail, Predictive maintenance based on earlier fault detection on multi phase induction machines using neural network artificial intelligent techniques, pp. 1612 - 1636

\section{Modeling of multiphase induction machines}

General theory of electric machines provides sufficient means for dealing with mathematical representation of an induction machine with an arbitrary number of phases on both stator and rotor. It can also effectively model machines with sinusoidally distributed windings and with concentrated windings, where one has to account for the higher spatial harmonics of the magneto-motive force. Probably, the most comprehensive treatment of the modeling procedure at a general level is available in [20]. More recently, detailed modeling of an n-phase induction machine, including the higher spatial harmonics, has been reported in [21], whereas specific case of a five-phase induction machine has been investigated in detail in [22,23]. Transformations of the phase-variable model are performed using appropriate real or complex matrix transformations, resulting in corresponding real or space vector models of the multiphase machine.

A slightly different approach to the multiphase machine modeling is discussed in [2425]. It is termed 'vectorial modeling' and it represents a kind of generalization of the space vector theory, applicable to all types of AC machines. In principle, it leads to the same control schemes for multiphase machines as do the transformations of the general theory of electric machines. This modeling approach is therefore not discussed further on. In what follows, a brief summary of the modeling procedure based on the general theory of electric machines is provided. An n-phase symmetrical induction machine, such that the spatial displacement between any two consecutive stator phases equals $\alpha=2 f / n$, is considered. Both stator and rotor windings are treated as n-phase and it is assumed that the windings are sinusoidally distributed, so that all higher spatial harmonics of the magnetomotive force can be neglected. The phase number $\mathrm{n}$ can be either odd or even. It is assumed that, regardless of the phase number, windings are connected in star with a single neutral point. The machine model in original form is transformed using decoupling (Clarke's) transformation matrix [20], which replaces the original sets of $n$ variables with new sets of $\mathrm{n}$ variables. Decoupling transformation matrix for an arbitrary phase number $\mathrm{n}$ can be given in power invariant.

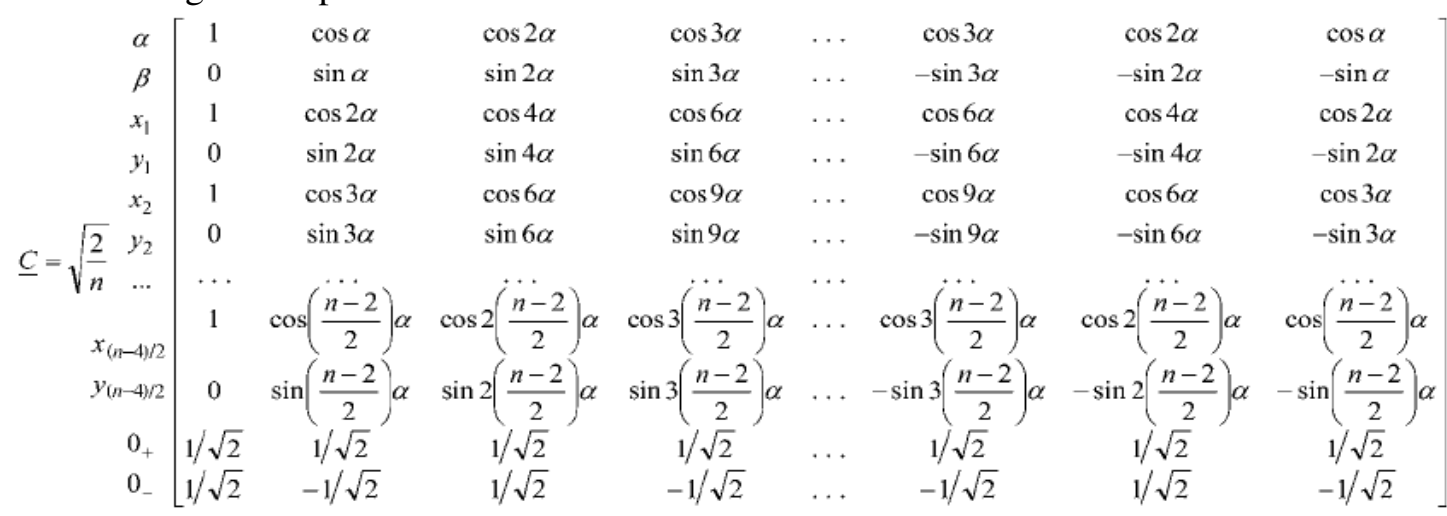

Fig. 1 Clarke's decoupling transformation matrix for a symmetrical n-phase system

Journal of Engineering Sciences, Assiut University, Faculty of Engineering, Vol. 41, No. 4, July, 2013, E-mail address: jes@aun.edu.eg 
Mohamed Mahmoud Ismail, Predictive maintenance based on earlier fault detection on multi phase induction machines using neural network artificial intelligent techniques, pp. 1612 - 1636

Form the Fig. 1 where $\rightarrow=2 f / n$. The first two rows of the matrix in Fig. 1 define variables that will lead to fundamental flux and torque production ( $\alpha, \downarrow$ components; stator to rotor coupling appears only in the equations for $\alpha, \downarrow$ components). The last two rows define the two zero sequence components and the last row of the transformation matrix in Fig. 1 is omitted for all odd phase numbers $n$. In Between, there are $(\mathrm{n}-4) / 2($ or $(\mathrm{n}-3) / 2$ for $n=$ odd) pairs of rows which define $(n-4) / 2$ (or $(n-3) / 2$ for $n=$ odd) pairs of variables, termed further on $\mathrm{x}-\mathrm{y}$ components. Equations for pairs of $\mathrm{x}-\mathrm{y}$ components are completely decoupled from all the other components and stator to rotor coupling does not appear either [20]. These components do not contribute to torque production when sinusoidal distribution of the flux around the air-gap is assumed. A zero-sequence component does not exist in any star-connected multiphase system without neutral conductor for odd phase numbers, while only $0_{-}$component can exist if the phase number is even. Since rotor winding is short circuited, neither $\mathrm{x}-\mathrm{y}$ nor zero-sequence components can exist, and one only needs to consider further on $\alpha, \downarrow$ equations of the rotor winding. As stator to rotor coupling takes place only in $\alpha, \downarrow$ equations, rotational transformation is applied only to these two pairs of equations. Its form is identical as for a three-phase machine. Assuming that the machine equations are transformed into an arbitrary frame of reference rotating at angular speed $\omega \mathrm{o}$, the model of an n-phase induction machine with sinusoidal winding distribution is given with:

$$
\begin{aligned}
& V_{s}=R_{s} I_{s}+\frac{d \psi_{s}}{d t}+\omega_{0} J_{2} \psi_{s} \\
& 0=R_{r} I_{r}+\frac{d \psi_{r}}{d t}+\left(\omega_{0}-\omega_{e}\right) \boldsymbol{J}_{2} \psi_{r} \\
& V_{x 1 s}=R_{s} I_{x 1 s}+p \psi_{x 1 s} \\
& V_{y 1 s}=R_{s} I_{y 1 s}+p \psi_{y 1 s} \\
& V_{x 2 s}=R_{s} I_{x 2 s}+p \psi_{x 2 s} \\
& V_{y 2 s}=R_{s} I_{y 2 s}+p \psi_{y 2 s} \\
& \ldots . . \\
& \ldots . . \\
& V_{o+s}=R_{s} I_{o+s}+p \psi_{o+s} \\
& V_{o-s}=R_{s} I_{o-s}+p \psi_{o-s} .
\end{aligned}
$$

Where; Vs is the stator phase voltage vector, Is is the stator phase current vector, Ir is the rotor phase current vector, $\mathrm{p}$ is the number of pole pairs, $\omega$ is the rotor speed, Rs is the stator phase resistance, $\mathrm{Rr}$ is the rotor phase resistance, $\Psi \mathrm{s}$ and $\Psi \mathrm{r}$ are the stator and rotor flux linkage vectors respectively. Equation (1) holds whether the induction motor magnetic circuit is considered linear or saturated and $\mathrm{J} 2$ is the $2 \times 2$ rotating matrix defined by $I_{2}=\left[\begin{array}{cc}0 & -1 \\ 1 & 0\end{array}\right]$

Journal of Engineering Sciences, Assiut University, Faculty of Engineering, Vol. 41, No. 4, July, 2013,E-mail address: jes@aun.edu.eg 
The mechanical equation can be expressed as:

$$
J \frac{d \omega}{d t}+b \omega=T-T_{L}
$$

$\left[\begin{array}{c}\boldsymbol{I}_{s} \\ \boldsymbol{I}_{r}\end{array}\right]=\left[\begin{array}{l}G_{s}\left(\| \psi_{s}\right) \\ \boldsymbol{G}_{r}\left(\| \psi_{r}\right)\end{array}\right]+\left[\begin{array}{cc}g_{l} \boldsymbol{I}_{2} & -g_{l} \boldsymbol{I}_{2} \\ -g_{l} \boldsymbol{I}_{2} & g_{l} \boldsymbol{I}_{2}\end{array}\right]\left[\begin{array}{l}\psi_{s} \\ \psi_{r}\end{array}\right]$

$I_{x 1 s}=g_{l} \psi_{x 1 s}$

$I_{y 1 s}=g_{l} \psi_{y 1 s}$

$I_{x 2 s}=g_{l} \psi_{x 2 s}$

$I_{y 2 s}=g_{l} \psi_{y 2 s}$

$I_{o+s}=g_{l} \psi_{o+s}$

$I_{o-s}=g_{l} \psi_{o-s}$

Where $\mathrm{gl}$ is defined as:

$$
\boldsymbol{g}_{l}=\frac{1}{\boldsymbol{L}_{l}}
$$

Where Gs and Gr are the stator and rotor vector-valued nonlinear functions and defined as:

$\mathrm{G}_{\mathrm{X}}\left(\psi_{\mathrm{X}}\right)=\mathrm{G}_{\mathrm{X}}\left(\left[\begin{array}{l}\psi_{\mathrm{Xd}} \\ \psi_{\mathrm{Xq}}\end{array}\right]\right)=\left[\begin{array}{l}\mathrm{I}_{\mathrm{mxd}} \\ \mathrm{I}_{\mathrm{mxq}}\end{array}\right]=\mathrm{I}_{\mathrm{mx}}$

Where; Im and $\Psi \mathrm{m}$ are the mutual current and flux vector, respectively, and subscript (x) can be (s) for stator and (r) for rotor. Equation (4) can be written as:

$\left[\begin{array}{c}\mathrm{I}_{\mathrm{S}} \\ \mathrm{I}_{\mathrm{r}}\end{array}\right]=\left[\begin{array}{cc}\left(\mathrm{g}_{\mathrm{S}}\left(\left\|\psi_{\mathrm{S}}\right\|\right)+\mathrm{g}_{\mathrm{l}}\right) \mathrm{I}_{2} & -\mathrm{g}_{1} \mathrm{I}_{2} \\ -\mathrm{g}_{1} \mathrm{I}_{2} & \left(\mathrm{~g}_{\mathrm{r}}\left(\left\|\psi_{\mathrm{S}}\right\|\right)+\mathrm{g}_{\mathrm{l}}\right) \mathrm{I}_{2}\end{array}\right]\left[\begin{array}{l}\psi_{\mathrm{S}} \\ \psi_{\mathrm{r}}\end{array}\right]$

Where; I2 is the $2 \times 2$ identity matrix, gl is defined as the reciprocal of the leakage inductance $(\mathrm{Ll})$, gs and gr are the stator and rotor vector-valued nonlinear saturation functions. The scalar saturation functions gs and gr only affect the magnitude, while

Journal of Engineering Sciences, Assiut University, Faculty of Engineering, Vol. 41, No. 4, July, 2013,E-mail address: jes@aun.edu.eg 
Mohamed Mahmoud Ismail, Predictive maintenance based on earlier fault detection on multi phase induction machines using neural network artificial intelligent techniques, pp. 1612 - 1636

keeping the directions of the fluxes and currents the same. These functions are monotone increasing and are non zero at the origin. The saturation functions $\operatorname{gs}(\mathrm{x})$ and $\operatorname{gr}(\mathrm{x})$ have to be identified experimentally for each motor as shown in the next section.

Finally, the generated torque (T) and $\mathrm{P}$ is the poles number is given by;

$$
\mathbf{T}=P g_{l}\left(\psi_{\mathrm{S}}\right)^{T} \mathbf{J}_{2}\left(\psi_{\mathbf{r}}\right)
$$

The model equations for equations (1), (5) and (9) are identical for the three phase induction motor. This means that in principle, the same control schemes will apply to multiphase induction machine as for the three phase machines. However, existence of $x-y$ equations means that utilization of a voltage source that creates stator voltage $x-y$ components will lead to a flow of potentially large stator $x-y$ current components, since there are restricted only by stator leakage impedance. In essence, $x-y$ components correspond to certain voltage and currents harmonics, the order of which depends on the machine number of the stator phases. Hence the inverter used to supply a multiphase induction machine must not create low voltage harmonics that will excite stator current low - order harmonic flow in $\mathrm{x}$-y circuit . Modeling of asymmetrical induction machines will again result in the same model equations (1)-(9), provided that an appropriate transformation matrix is applied. The decoupling transformation matrix for asymmetrical five and six-phase machine with two isolated neutral points is of the form In equation (10) and (11) respectively, where the first three elements in each row are related to the three phase model of induction motor with the assumption that in (10) and (11) that neutral points of the two three-phase windings are not connected, in conjunction with the subsequent rotational transformation again results in model equations (1)-(9), where there is a single pair of $x-y$ component equations (x1-y1) and zero-sequence equations do not exist.

$$
\begin{aligned}
& \underline{C}=\sqrt{\frac{2}{5}} \begin{array}{c}
\alpha \\
y \\
0
\end{array} \mid\left[\begin{array}{ccccc}
1 & \cos \alpha & \cos 2 \alpha & \cos 3 \alpha & \cos 4 \alpha \\
0 & \sin \alpha & \sin 2 \alpha & \sin 3 \alpha & \sin 4 \alpha \\
1 & \cos 2 \alpha & \cos 4 \alpha & \cos 6 \alpha & \cos 8 \alpha \\
0 & \sin 2 \alpha & \sin 4 \alpha & \sin 6 \alpha & \sin 8 \alpha \\
1 / \sqrt{2} & 1 / \sqrt{2} & 1 / \sqrt{2} & 1 / \sqrt{2} & 1 / \sqrt{2}
\end{array}\right] \\
& \underline{C}=\sqrt{\frac{2}{6} x_{1}} \begin{array}{c}
\beta \\
y_{1} \\
O_{+}
\end{array}\left[\begin{array}{ccccccc}
1 & \cos \frac{2 \pi}{3} & \cos \frac{4 \pi}{3} & \cos \frac{\pi}{6} & \cos \frac{5 \pi}{6} & \cos \frac{9 \pi}{6} \\
0 & \sin \frac{2 \pi}{3} & \sin \frac{4 \pi}{3} & \sin \frac{\pi}{6} & \sin \frac{5 \pi}{6} & \sin \frac{9 \pi}{6} \\
1 & \cos \frac{4 \pi}{3} & \cos \frac{8 \pi}{3} & \cos \frac{5 \pi}{6} & \cos \frac{\pi}{6} & \cos \frac{9 \pi}{6} \\
0 & \sin \frac{4 \pi}{3} & \sin \frac{8 \pi}{3} & \sin \frac{5 \pi}{6} & \sin \frac{\pi}{6} & \sin \frac{9 \pi}{6} \\
0 & 0 & 0 & 0 & 0 & 0 \\
O_{-} & 0 & 1 & 1 & 1
\end{array}\right]
\end{aligned}
$$

Journal of Engineering Sciences, Assiut University, Faculty of Engineering, Vol. 41, No. 4, July, 2013,E-mail address: jes@aun.edu.eg 
1619

Mohamed Mahmoud Ismail, Predictive maintenance based on earlier fault detection on multi phase induction machines using neural network artificial intelligent techniques, pp. 1612 - 1636

As the number of phases of an induction machine increases it becomes progressively difficult to achieve sinusoidal distribution of the magneto-motive force, because of the limited number of slots along the stator circumference. On the other hand, sinusoidal distribution is actually often not even a desirable feature of a multiphase machine.

\section{Fault detection identification}

The new in this paper is the online detection of the motor fault conditions using neural network and ANFIS techniques. The induction motor monitoring diagnosis techniques such that magnetic flux, vibration, stator currents, induced voltage, power and surge testing are used for detection of the motor faults. The stator current signal are contains potential fault information and is the most suitable measurements for diagnosing the faults under consideration, in term of easy accessibility, reliability, and sensitivity. A simple construction using stator current for motor fault detection is indicated in figure2, the linguistic variables of the induction motor stator conditions are shown in figure 3 .

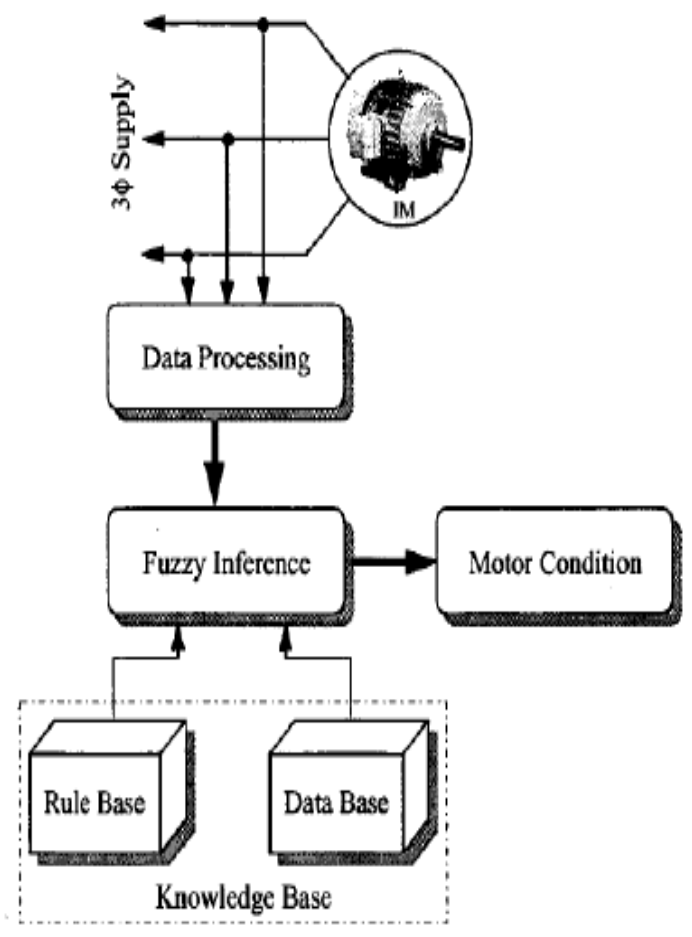

Fig. 2 Block diagram of induction motor condition monitoring system

Journal of Engineering Sciences, Assiut University, Faculty of Engineering, Vol. 41, No. 4, July, 2013,E-mail address: jes@aun.edu.eg 


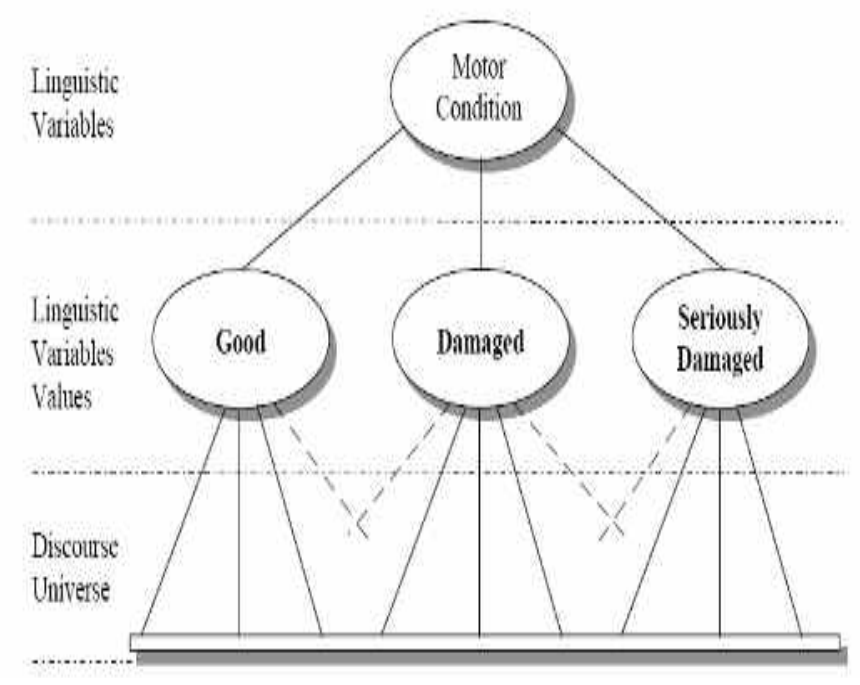

Fig. 3 Linguistic variables of the induction motor stator condition

\section{Artificial intelligent techniques}

\section{1. Neuro fuzzy controller}

A list of industrial applications and home appliances based on FLC can be found in several recent references [39 to 45]. An adaptive neuro -Fuzzy Inference System (ANFIS) is a cross between an Artificial Neural Network (ANN) and a fuzzy inference system (FIS). An artificial neural network is designed to simulate the characteristics of the human brain and consists of a collection of artificial neurons. An adaptive network is a multi-layer feed-forward network in which each node (neuron) performs a particular function on incoming signals. The form of the node functions may vary from node to node. In an adaptive network, there are two types of nodes, adaptive and fixed. The function and the grouping of the neurons are dependent on the overall function of the network. Based on the ability of an ANFIS to learn from training data, it is possible to create an ANFIS structure from an extremely limited mathematical representation of the system. In sequel, the ANFIS architecture can identify the near-optimal membership functions of FLC for achieving desired input-output mappings. The network applies a combination of the least squares method and the back propagation gradient descent method for training FIS membership function parameters to emulate a given training data set. The system converges when the training and checking errors are within an acceptable bound. The ANFIS system generated by the fuzzy toolbox available in MATLAB allows for the generation of a standard Sugeno style fuzzy inference system or a fuzzy inference system based on sub-clustering of the data. Figure 2 shows a simple two-input ANFIS architecture. The above ANFIS architecture is based on a Sugeno fuzzy inference system.

Journal of Engineering Sciences, Assiut University, Faculty of Engineering, Vol. 41, No. 4, July, 2013,E-mail address: jes@aun.edu.eg 
1621

Mohamed Mahmoud Ismail, Predictive maintenance based on earlier fault detection on multi phase induction machines using neural network artificial intelligent techniques, pp. 1612 - 1636

The Sugeno FIS is similar to Mamadani format except the output memberships are singleton spikes rather than a distributed fuzzy set. Using singleton output simplifies the defuzzification step.

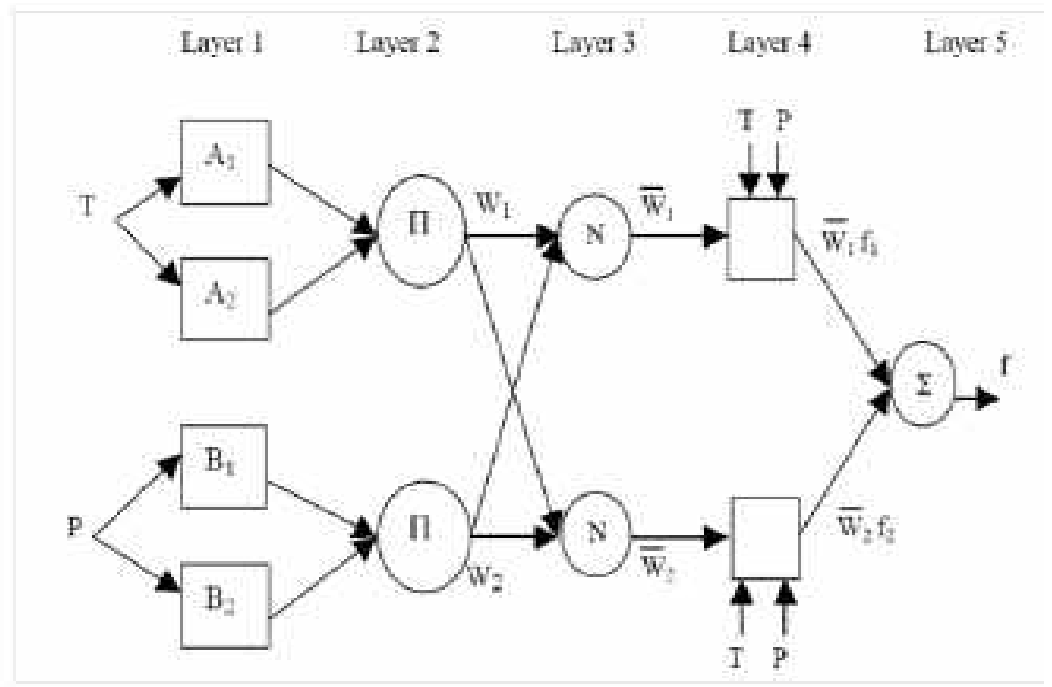

Fig. 4 ANFIS Architecture for a Two-Input System

The ANFIS network shown in Figure (4) is composed of five layers. Each node in the first layer is a square (adaptive) node with a node function. The basic diagram computation in ANFIS is sown in Figure (5). This structure contains the same components as the FIS, expect for the NNblock. The structure of the network is composed of a set of units (and connections) arranged into five connected network layers.

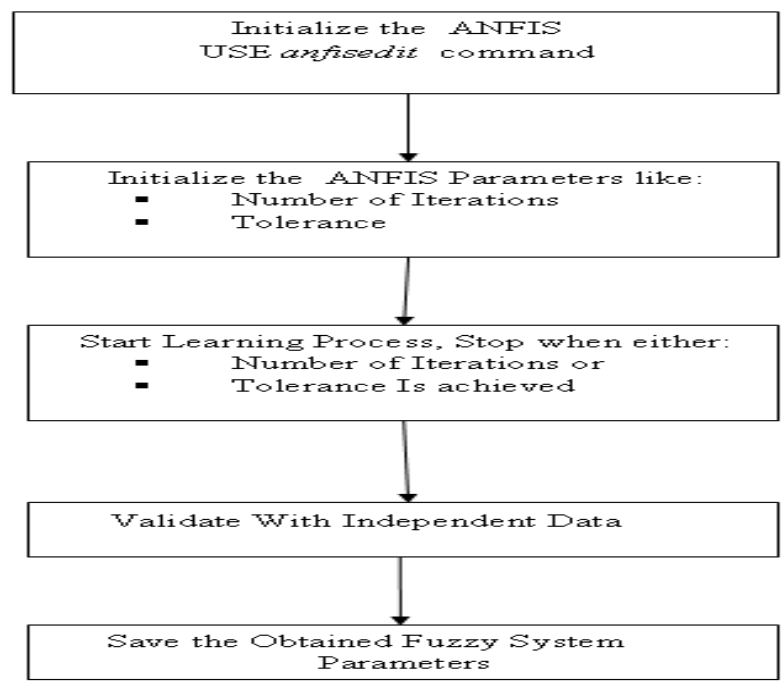

Fig. 5 Basic Diagram of ANFIS Computation

Journal of Engineering Sciences, Assiut University, Faculty of Engineering, Vol. 41, No. 4, July, 2013,E-mail address: jes@aun.edu.eg 
Mohamed Mahmoud Ismail, Predictive maintenance based on earlier fault detection on multi phase induction machines using neural network artificial intelligent techniques, pp. 1612 - 1636

Layer 1 : This layer consists of input variables (membership functions), via., input $1 \&$ input 2. Here, triangular or bell shaped MF can be used. This layer just supplies the input values $\mathrm{x}$ to the next layer, where $\mathrm{i}=1$ to $\mathrm{n}$.Layer 2 : This layer (membership layer) checks for the weights of each MFs. It receives the input values $x$ from the 1 st layer and act as MFs to represent the fuzzy sets of the respective input variables. Further, it computes the membership values which specify the degree to which the input value $\mathrm{x}$ belongs to the fuzzy set, which acts as the inputs to the next layer.

Layer 3 : This layer is called as the rule layer. Each node (each neuron) in this layer performs the pre-condition matching of the fuzzy rules, i.e., they compute the activation level of each rule, the number of layers being equal to the number of fuzzy rules. Each node of these layers calculates the weights which are normalized.

Layer 4 : This layer is called as the defuzzification layer and provides the output values $y$ resulting from the inference of rules. Connections between the layers 13 and 14 are weighted by the fuzzy singletons that represent another set of parameters for the neuro fuzzy network. Layer 5 : This layer is called as the output layer which sums up all the inputs coming from the layer 4 and transforms the fuzzy classification results into a crisp (binary). The ANFIS structure is tuned automatically by least-square estimation as well as the back propagation algorithm. The algorithm shown above is used in the next section to develop the ANFIS technique to control the various parameters of the induction motor. Because of its flexibility, the ANFIS strategy can be used for a wide range of control applications.

\section{2. ANFIS design for motor fault detection conditions}

The main purpose of using ANFIS controller in this paper is for identification of the fault occurrence in the saturated model of induction motor. The ANFIS controller structure is shown in Figure (6) . The fuzzy logic membership functions for the input and output are turned using neural network method which is well known in MATLAB program as ANFIS structure. The parameters are selected such that, optimization method is hybrid, the membership function is gbellmf , the membership function output is linear, error tolerance was chosen to be 0.01 , the no of epochs are 1000 , grid partitions , the inputs of the grid partitions are the number MFS are 3 , MF type is gbellmf, the outputs is MF type defined to be constant. The motor parameters that used in simulation are shown in table 1.

Table 1.

Motor parameters

\begin{tabular}{|c|c|c|}
\hline Parameters & $\pi$ - Model & Unit \\
\hline$R_{s}$ & 8 & $\Omega$ \\
\hline$R_{r}$ & 6 & $\Omega$ \\
\hline$L_{\sigma s}$ & $\mathrm{NA}$ & $\mathrm{H}$ \\
\hline$L_{\sigma r}$ & $\mathrm{NA}$ & $\mathrm{H}$ \\
\hline$L m$ & $\mathrm{NA}$ & $\mathrm{H}$ \\
\hline$L_{I}$ & 0.062 & $\mathrm{H}$ \\
\hline$J$ & 0.06 & $\mathrm{Kgm}^{2}$ \\
\hline$B$ & 0.04 & $\mathrm{No} / \mathrm{Rad}$ \\
\hline
\end{tabular}

Journal of Engineering Sciences, Assiut University, Faculty of Engineering, Vol. 41, No. 4, July, 2013,E-mail address: jes@aun.edu.eg 


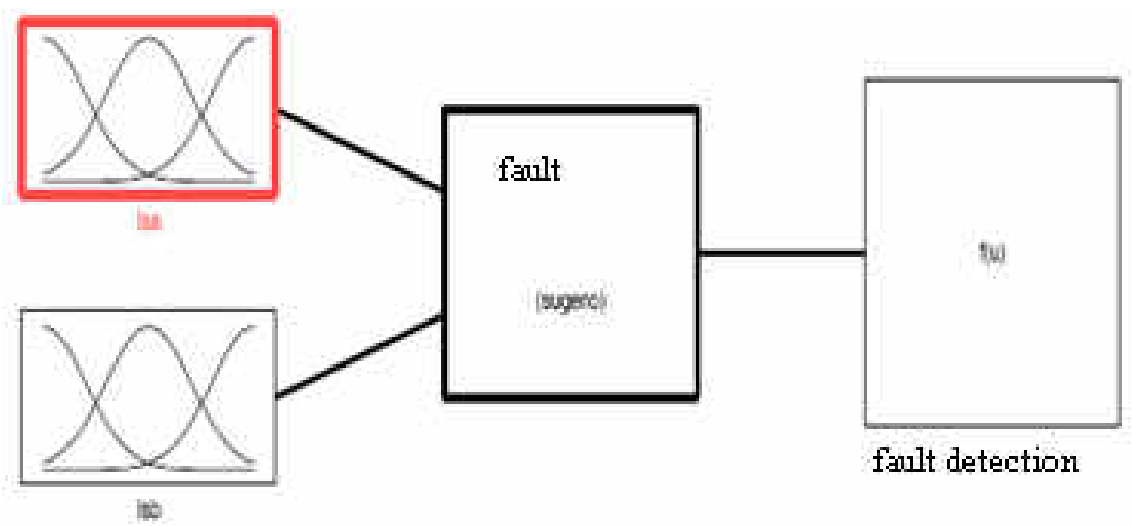

Fig. 6 Fault detection controller using ANFIS

\section{3. Neural Network}

A neural network $(\mathrm{NN})$ is a machine like human brain with properties of learning capability and generalization. It requires a lot of training to understand the model of plant. The basic property of this network is capability to learn the characteristic of nonlinear dynamic system mappings. The neural network consists as shown in figure (7) of three layers, an input layer, one or more hidden layers and an output layer. Neurons of hidden and output layers have an activation functions. The knowledge of $\mathrm{NN}$ can be achieved through a learning algorithm process [46-50]. In this paper, the inputs to the ANN block is the stator currents Isa and Isb while the output is the fault detection signals .

To create the block ANN switching table we passed by this program MATLAB. The MATLAB $m$ file can be written as following :

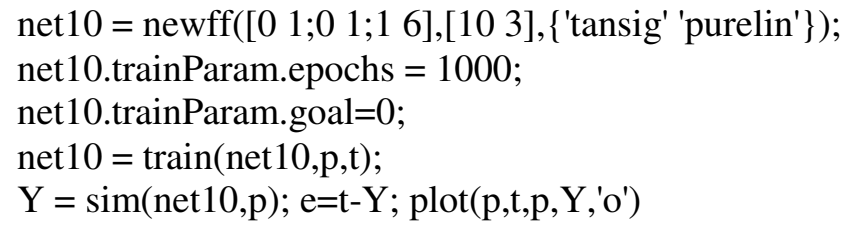

In MATLAB command we generate the SIMULINK block ANN of switching table by "'gensim

(net10)", the model generated is shown in figure 8

Journal of Engineering Sciences, Assiut University, Faculty of Engineering, Vol. 41, No. 4, July, 2013,E-mail address: jes@aun.edu.eg 


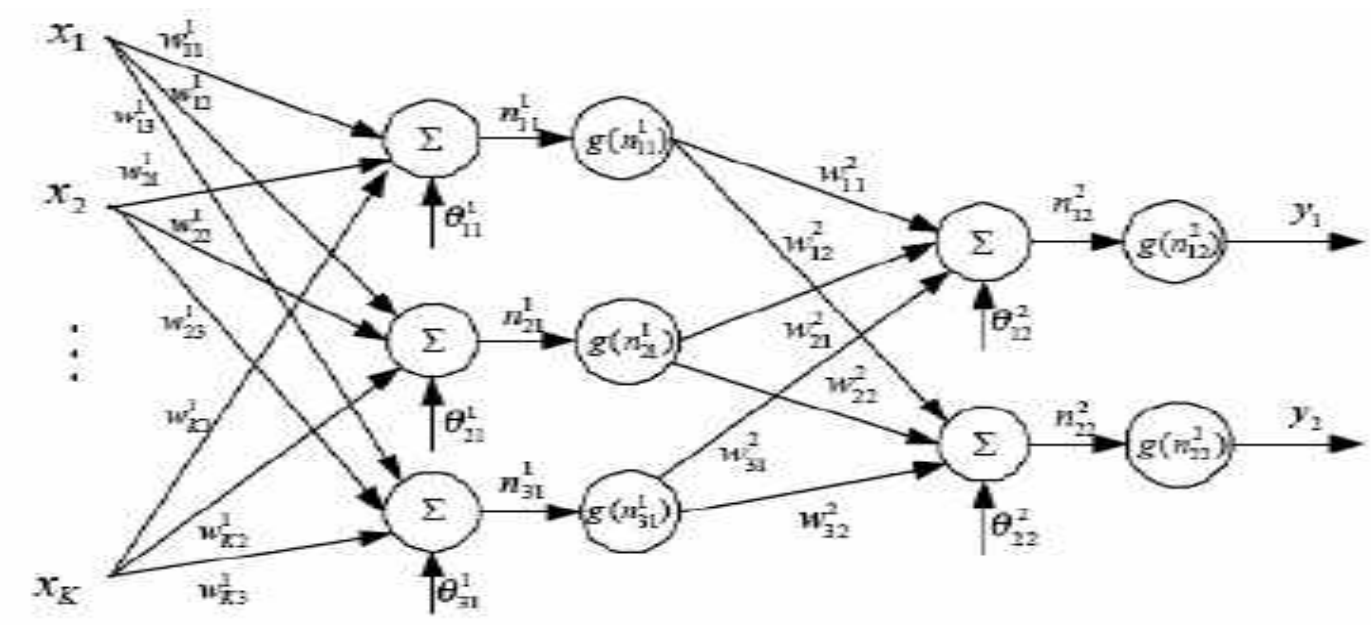

Input layer

Hidden layer

Output layer

Fig. 7 Structure of neural network

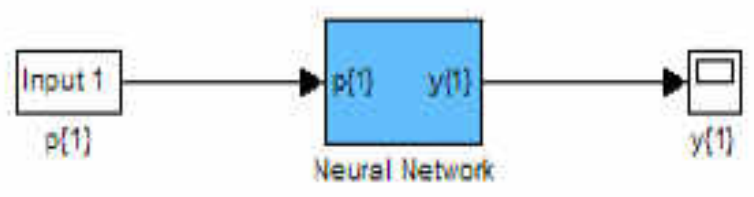

Fig. 8 ANN block in MATLAB simulink

\section{Simulations}

Using MATLAB SIMULINK program have been performed for simulation the five and six phase saturated model of the induction machines .A comparison is illustrated between the saturated model of induction motor behavior between of the three, five and six phase models .

Using the saturated model of the three phase induction motor with the parameters in table 1 , the applied supply voltage are $: \mathrm{Ua}=380 \sin (2 \pi 50 \mathrm{t}), \mathrm{Ub}=380 \sin (2 \pi 50 \mathrm{t}-$ $2 \Pi / 3), U c=380 \sin (2 \Pi 50 t+2 \pi / 3)$ the simulation duration is 100 second .

Journal of Engineering Sciences, Assiut University, Faculty of Engineering, Vol. 41, No. 4, July, 2013,E-mail address: jes@aun.edu.eg 
1625

Mohamed Mahmoud Ismail, Predictive maintenance based on earlier fault detection on multi phase induction machines using neural network artificial intelligent techniques, pp. 1612 - 1636

\section{1. Simulation 1}

A comparison is performed between the three phase saturated model with the five and six phase saturated model in normal operation without faults, the results of the simulation are specified in figures (9) to figure (13)

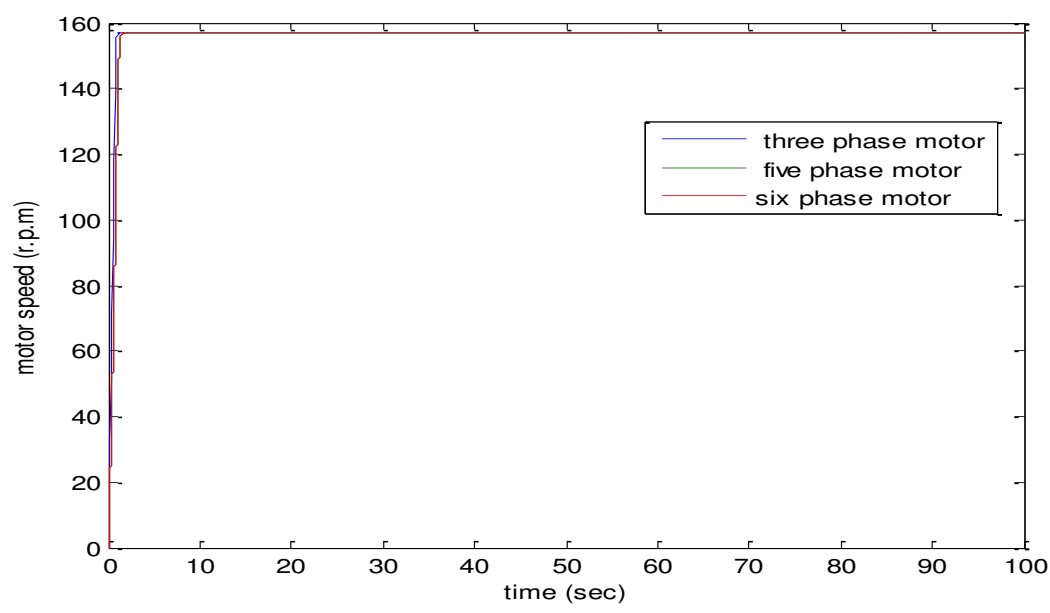

Fig. 9 Motor speed for simulation 1

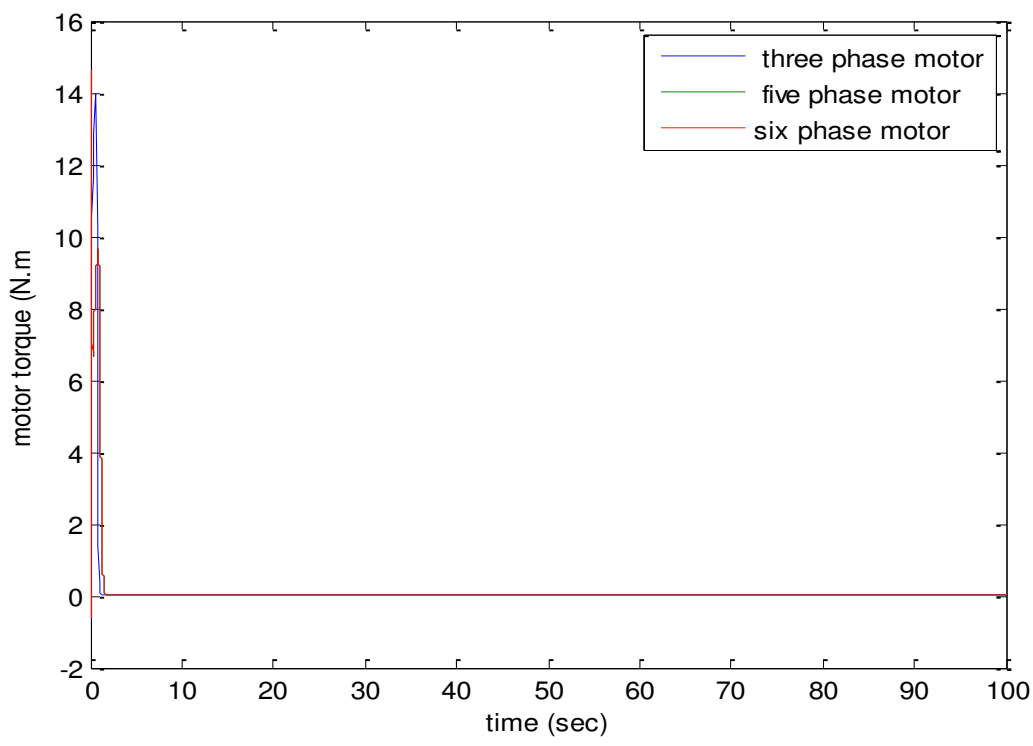

Fig. 10 Motor load torques for simulation 1

Journal of Engineering Sciences, Assiut University, Faculty of Engineering, Vol. 41, No. 4, July, 2013,E-mail address: jes@aun.edu.eg 
Mohamed Mahmoud Ismail, Predictive maintenance based on earlier fault detection on multi phase induction machines using neural network artificial intelligent techniques, pp. 1612 - 1636

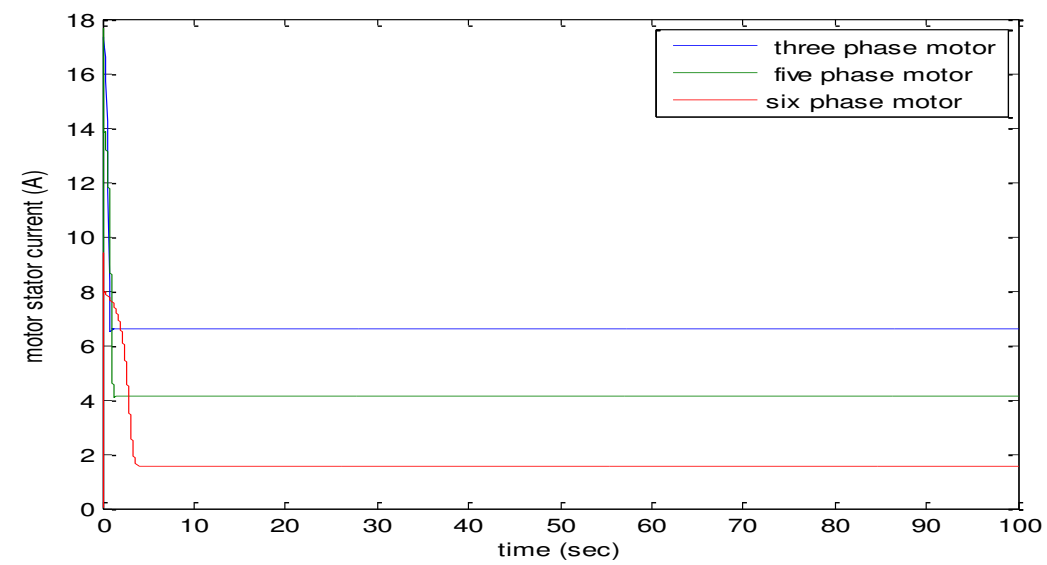

Fig. 11 Motor Stator current for simulation 1

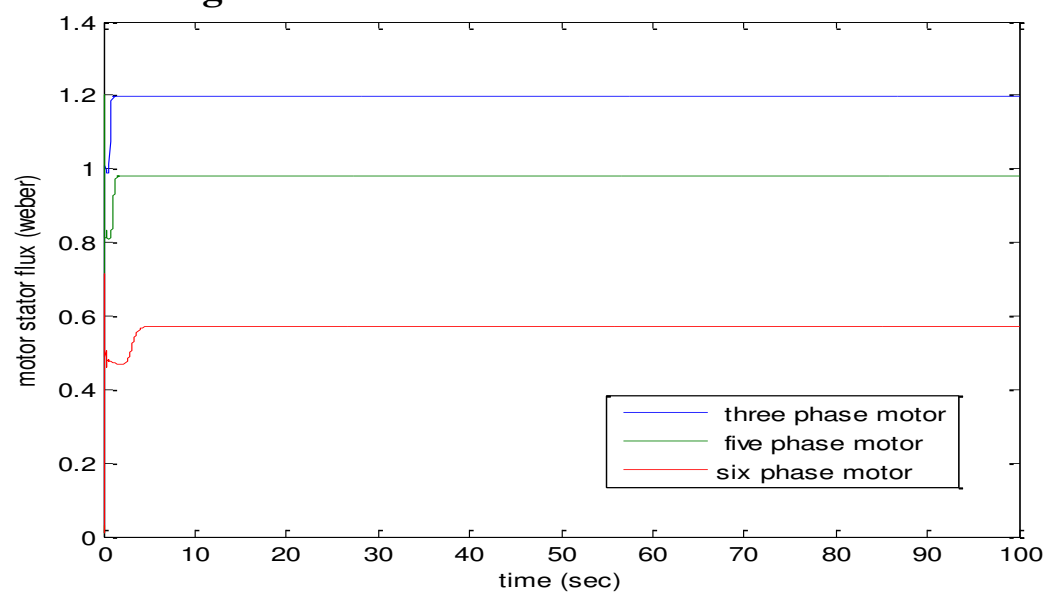

Fig. 12 Motor Stator flux Magnitude for simulation 1

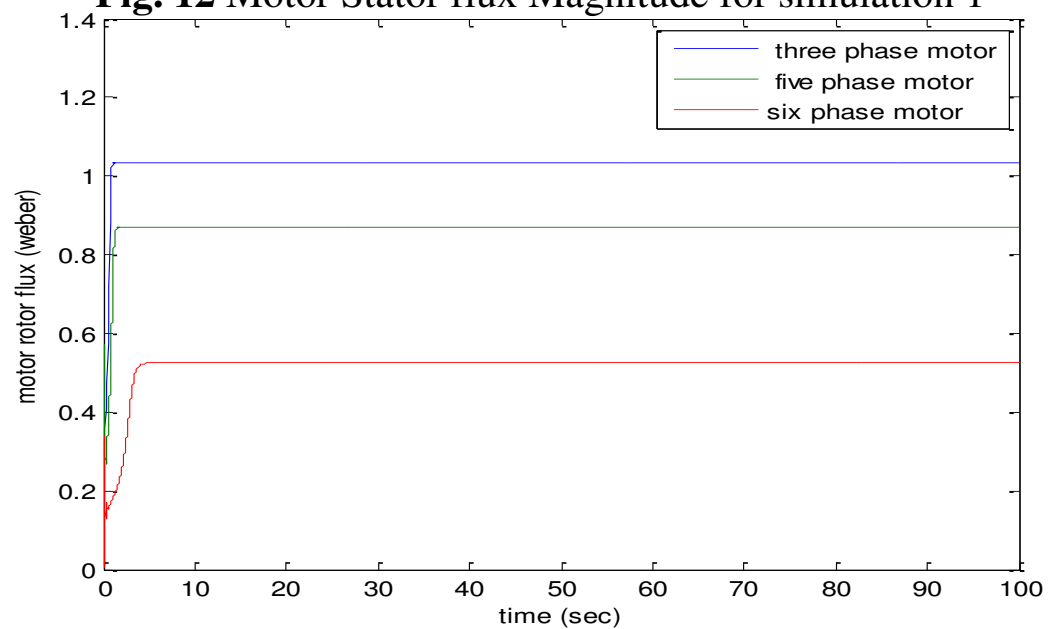

Fig. 13 Motor Rotor flux Magnitude for simulation 1

Journal of Engineering Sciences, Assiut University, Faculty of Engineering, Vol. 41, No. 4, July, 2013,E-mail address: jes@aun.edu.eg 
Mohamed Mahmoud Ismail, Predictive maintenance based on earlier fault detection on multi phase induction machines using neural network artificial intelligent techniques, pp. 1612 - 1636

From the simulation results, the speed and load torque are the same using three and five and six phase saturated motor model for the same supply voltage and load torque and same motor parameters. But the stator currents and stator and rotor fluxes are decreases in the six phases more than five and three phases respectively. That indicate by using the multiphase induction machine give the same output of the three phase motor ( speed and load torque ) but we decrease the currents and fluxes in the motor winding which is more better for the motor life time and operating conditions .

\section{2. Simulation 2}

Using the saturated model of the three phase induction motor with the parameters in table 1 , the applied supply voltage are $: \mathrm{Ua}=380 \sin (2 \Pi 50 \mathrm{t}), \mathrm{Ub}=380 \sin (2 \Pi 50 \mathrm{t}-$ $2 \Pi / 3), U c=380 \sin (2 \Pi 50 \mathrm{t}+2 \Pi / 3)$ the simulation duration is 20 second .

Start the simulation on the three phase induction motor by performing the different fault conditions stated before and plotting the effect of the faults on the measured signals of the stator currents. The result of the simulation is indicated in figures 14 to 20 .

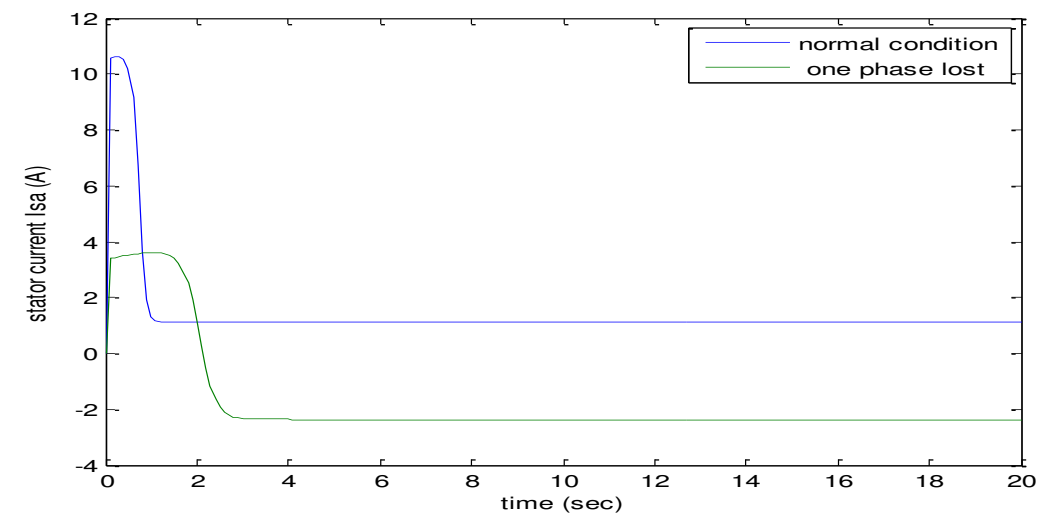

Fig.14 Stator current Isa in case of one phase is lost or line to ground fault of the three phase motor supply

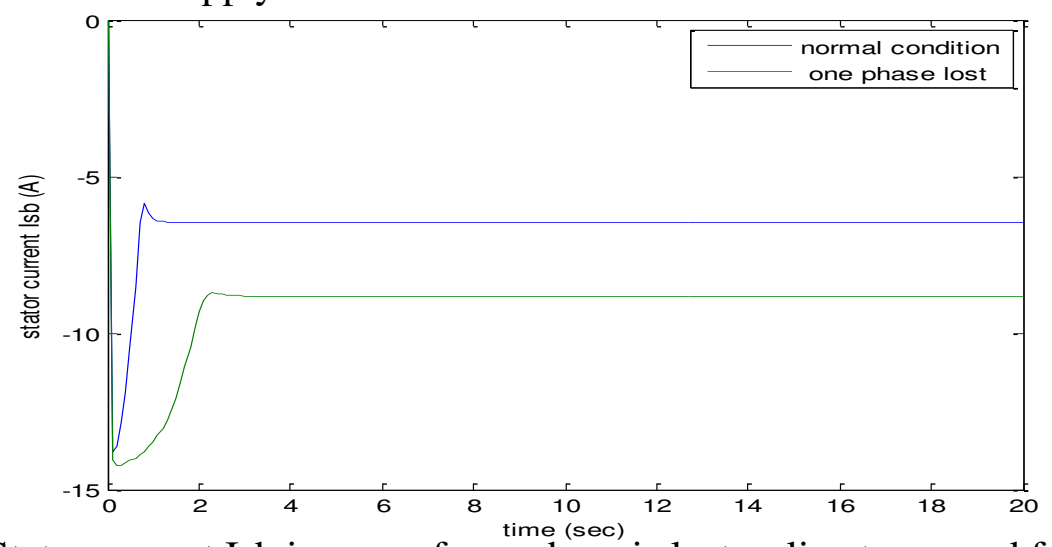

Fig. 15 Stator current Isb in case of one phase is lost or line to ground fault of the three phase motor supply

Journal of Engineering Sciences, Assiut University, Faculty of Engineering, Vol. 41, No. 4, July, 2013,E-mail address: jes@aun.edu.eg 
Mohamed Mahmoud Ismail, Predictive maintenance based on earlier fault detection on multi phase induction machines using neural network artificial intelligent techniques, pp. 1612 - 1636

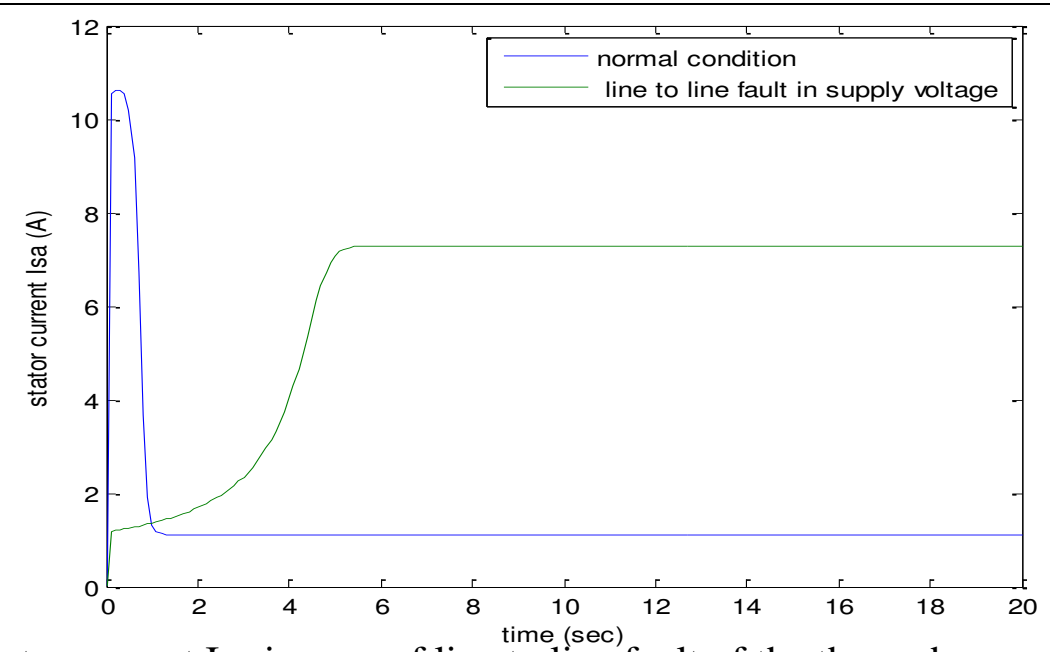

Fig.16 Stator current Isa in case of line to line fault of the three phase motor supply

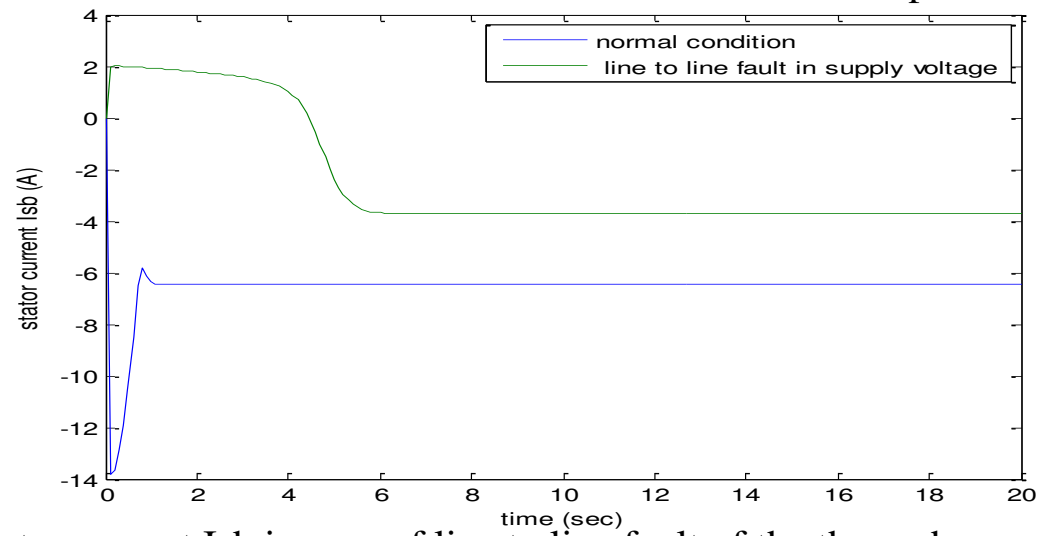

Fig. 17 Stator current Isb in case of line to line fault of the three phase motor supply

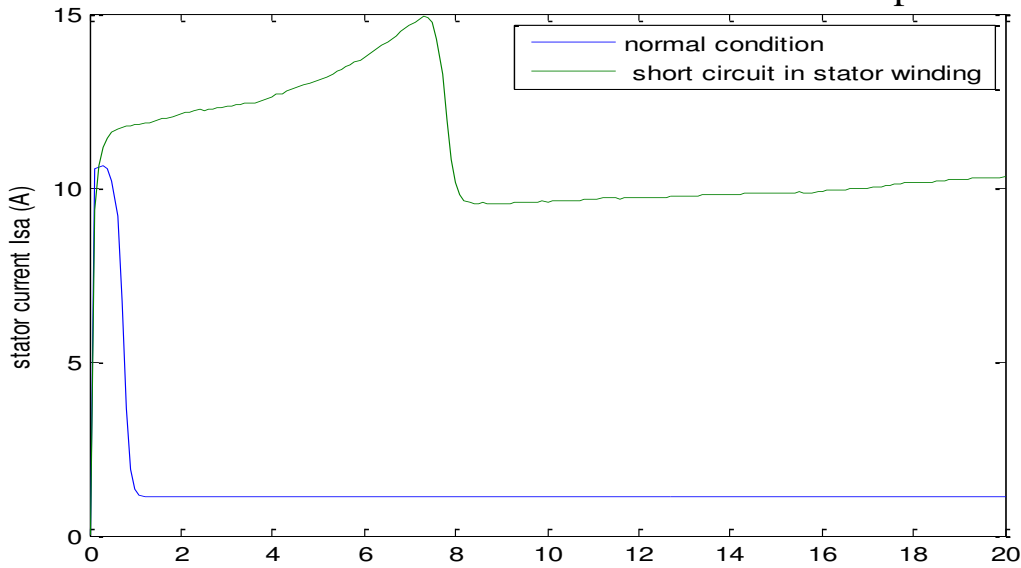

Fig. 18 Stator current Isa in case short cimercult in the stator windings of the three phase motor

Journal of Engineering Sciences, Assiut University, Faculty of Engineering, Vol. 41, No. 4, July, 2013,E-mail address: jes@aun.edu.eg 
Mohamed Mahmoud Ismail, Predictive maintenance based on earlier fault detection on multi phase induction machines using neural network artificial intelligent techniques, pp. 1612 - 1636

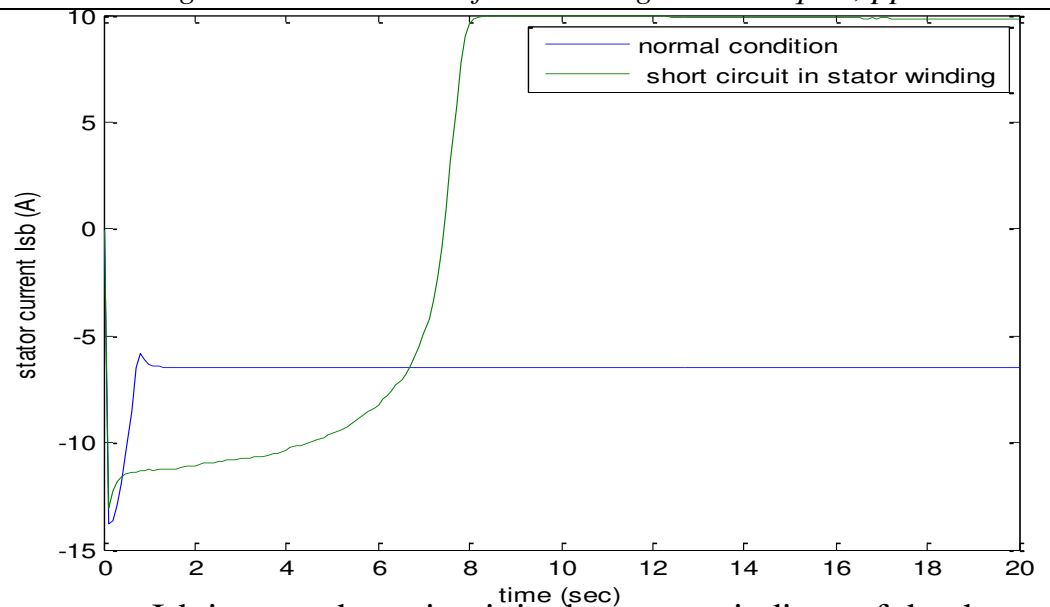

Fig. 19. Stator current Isb in case short circuit in the stator windings of the three phase motor

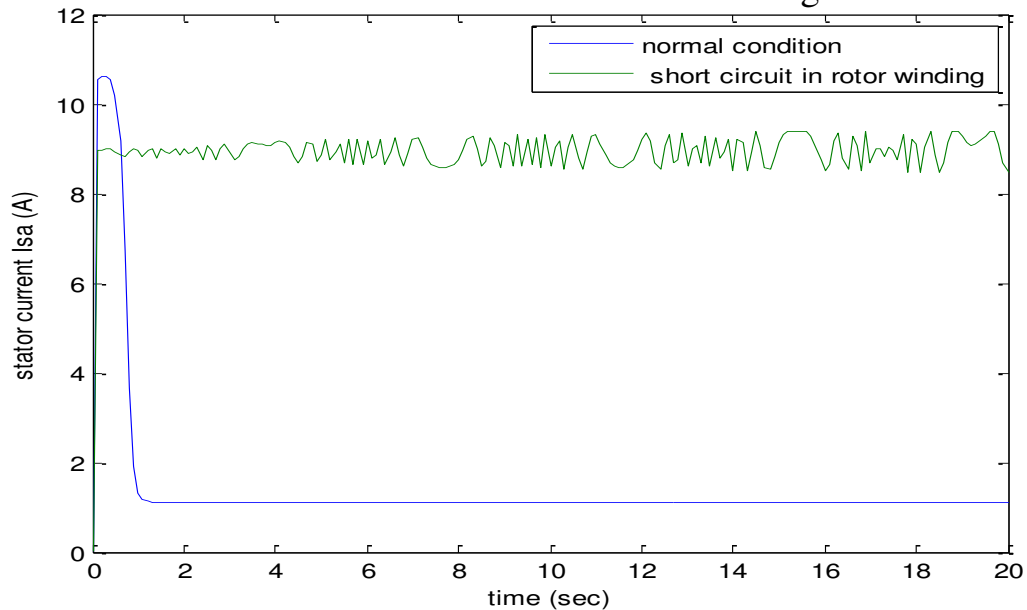

Fig. 20. Stator current Isa in case short circuit in the rotor windings of the three phase motor

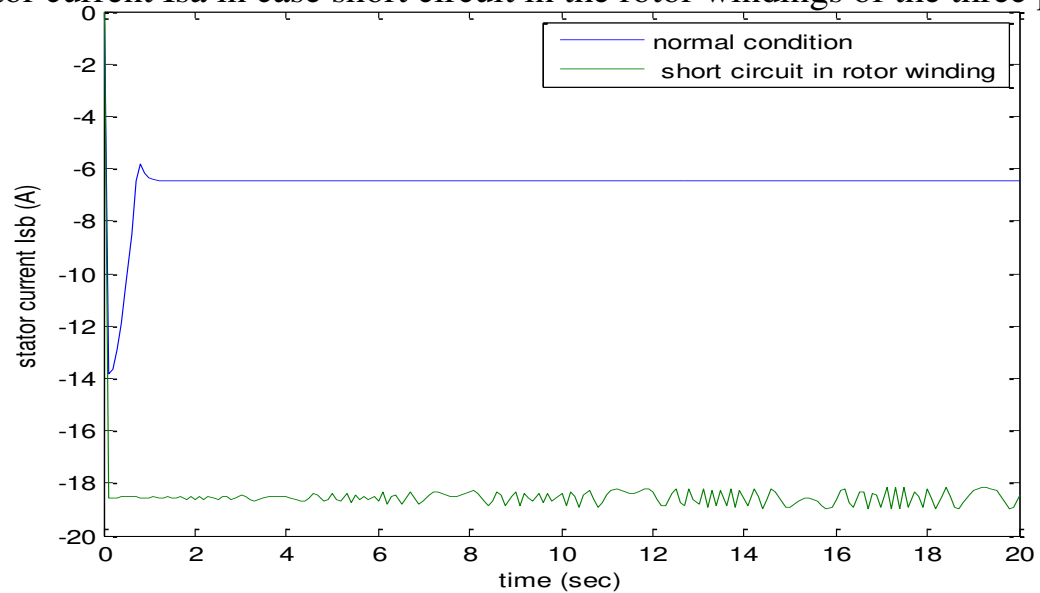

Fig. 21. Stator current Isb in case short circuit in the rotor windings of the three phase motor

Journal of Engineering Sciences, Assiut University, Faculty of Engineering, Vol. 41, No. 4, July, 2013,E-mail address: jes@aun.edu.eg 
Mohamed Mahmoud Ismail, Predictive maintenance based on earlier fault detection on multi phase induction machines using neural network artificial intelligent techniques, pp. 1612 - 1636

\section{3. Simulation 3}

Using the saturated model of the five and six phase induction motor with the same parameters in table 1 , the applied supply voltage are : $\mathrm{Ua}=380 \sin (2 \Pi 50 \mathrm{t}), \mathrm{Ub}=380$ $\sin (2 \Pi 50 t-2 \Pi / 3), U c=380 \sin (2 \pi 50 t+2 \pi / 3)$ the simulation duration is 100 second . Start the simulation on the three phase induction motor by performing the different fault conditions stated before and plotting the effect of the faults on the measured signals of the stator currents. The result of the simulation is indicated in figures 22 to 25

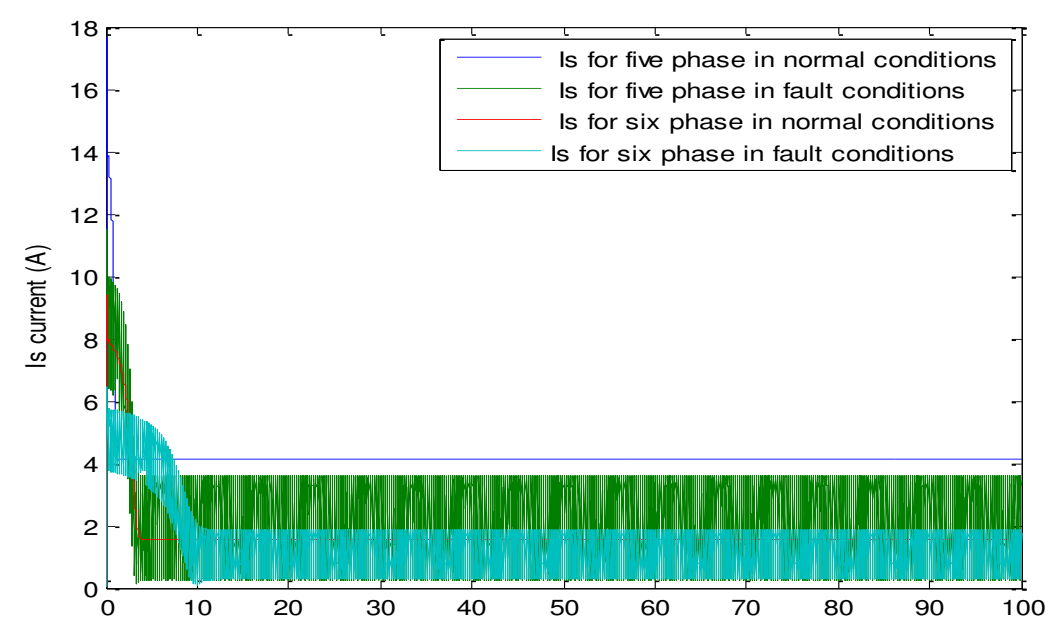

Fig. 22. Stator current Is in case of onetimph (şse is lost or line to ground fault of the motor supply for five and six phase saturated model of induction motor

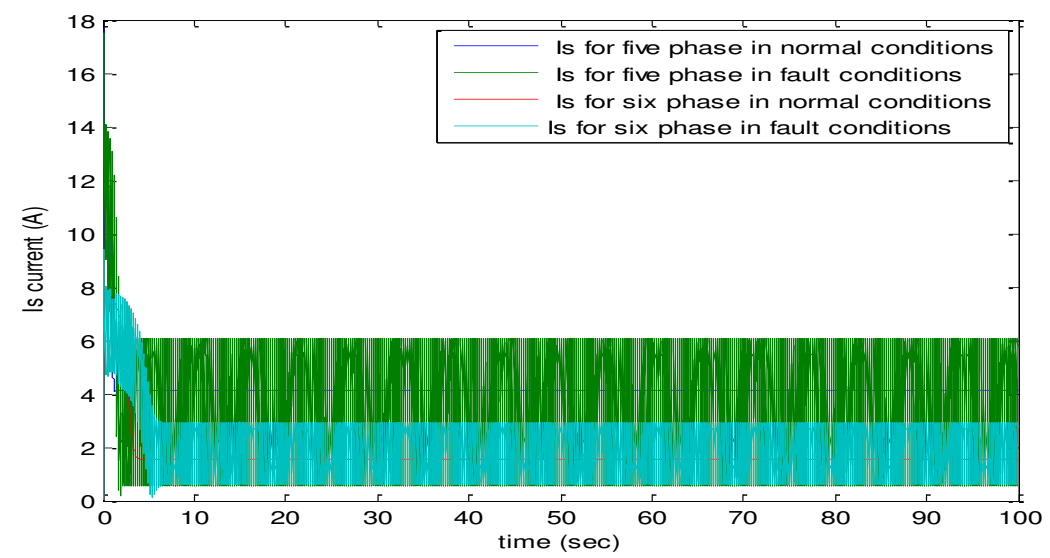

Fig. 23. Stator current Is in case of line to line fault of the motor supply for five and six phase saturated model of induction motor

Journal of Engineering Sciences, Assiut University, Faculty of Engineering, Vol. 41, No. 4, July, 2013,E-mail address: jes@aun.edu.eg 
Mohamed Mahmoud Ismail, Predictive maintenance based on earlier fault detection on multi phase induction machines using neural network artificial intelligent techniques, pp. $1612-1636$

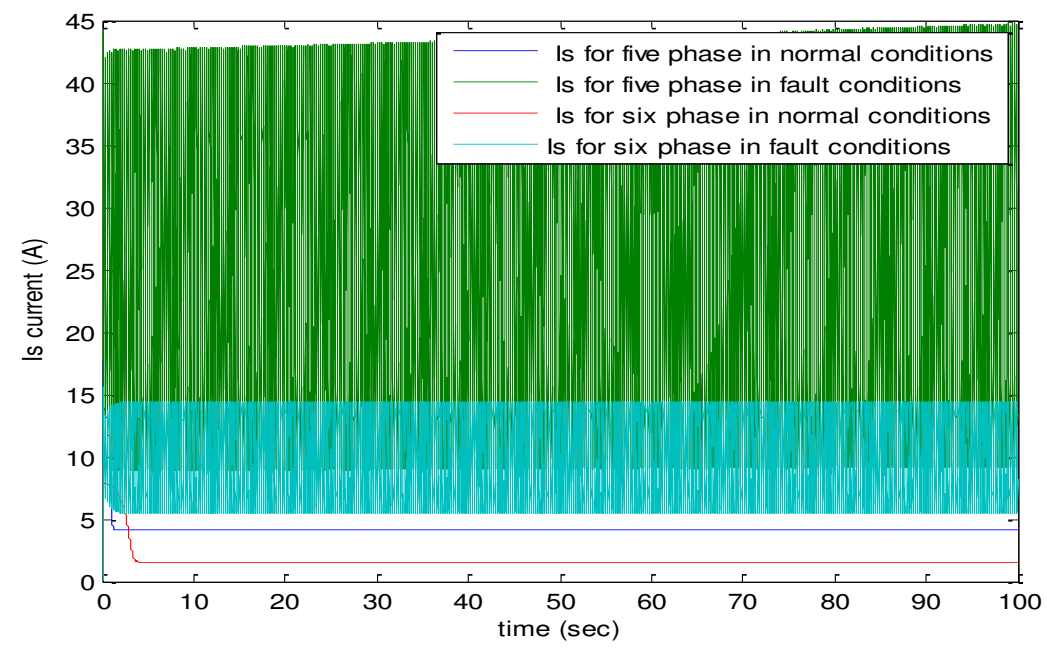

Fig. 24. Stator current Is in case of short circuit of stator winding for five and six phase saturated model of induction motor

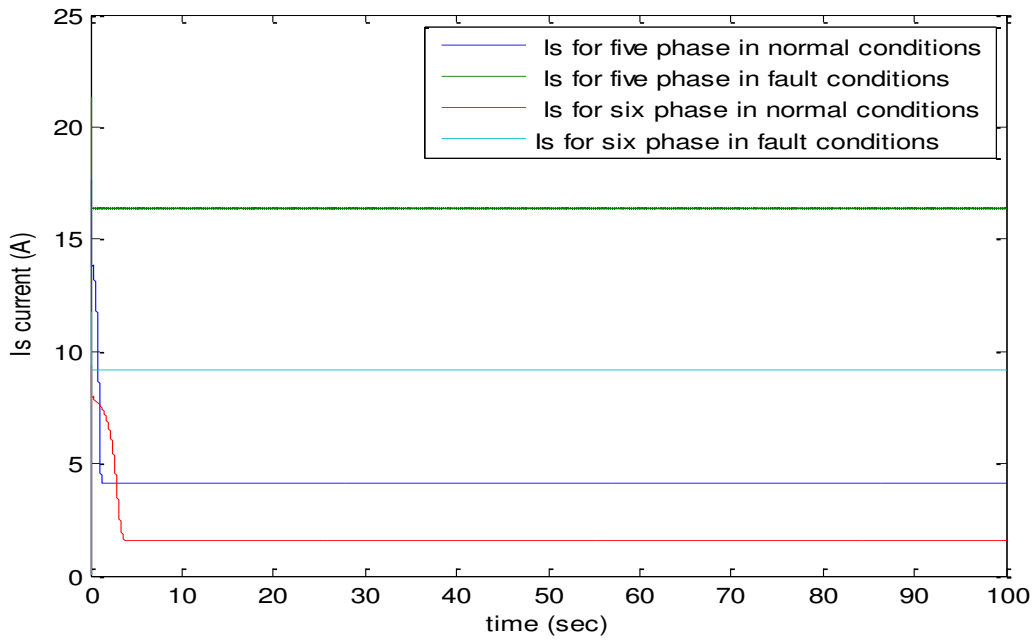

Fig. 25. Stator current Is in case of short circuit in the rotor windings for five and six phase saturated model of induction motor

\section{4. simulation 4}

Using ANFIS controller with neural network technique for online detection of the type of fault that occur to the induction motor as following, table 2 give the expected values that the ANFIS and neural network must expect. Table 3 gives the results of simulations in case of three phase induction motor. However table 4 and 5 give the results of simulations in case of five and six phase induction motor respectively.

Journal of Engineering Sciences, Assiut University, Faculty of Engineering, Vol. 41, No. 4, July, 2013,E-mail address: jes@aun.edu.eg 
Mohamed Mahmoud Ismail, Predictive maintenance based on earlier fault detection on multi phase induction machines using neural network artificial intelligent techniques, pp. 1612 - 1636

\section{Table 2.}

Expected values for ANFIS and neural network of different operating conditions

\begin{tabular}{|c|c|c|c|}
\hline Item & Type of fault & ANFIS output & $\begin{array}{c}\text { Neural } \\
\text { Network } \\
\text { output }\end{array}$ \\
\hline 1 & $\begin{array}{c}\text { Normal operating } \\
\text { conditions }\end{array}$ & 0 & 0 \\
\hline 2 & $\begin{array}{c}\text { One phase loss or line to } \\
\text { ground fault }\end{array}$ & 1 & 1 \\
\hline 3 & Line to line fault & 2 & 2 \\
\hline 4 & $\begin{array}{c}\text { Short circuit in the stator } \\
\text { winding }\end{array}$ & 3 & 3 \\
\hline 5 & $\begin{array}{c}\text { Short circuit in the rotor } \\
\text { winding }\end{array}$ & 4 & 4 \\
\hline
\end{tabular}

We start the simulation using ANFIS and neural network techniques for detecting the status of the motor during the motor operation which can be used for predictive maintenance of the induction motors in the industrial factories. We are applying different operating conditions using simulations.

Such that

1- One phase lost of the motor power supply ( or line to ground fault )

2- Line to line fault of the motor power supply

3- Short circuit in the stator winding of induction motor

4- Short circuit in the rotor winding of induction motor

The test is applied on three types of the induction motor (three phase - five phase - six phase) induction motor. The tables below show the response of the ANFIS and neural network at different operating conditions.

Table 3.

Fault detection for three phase induction motor

\begin{tabular}{|l|l|c|c|c|}
\hline Item & \multicolumn{1}{|c|}{ Type of fault } & $\begin{array}{c}\text { Expected } \\
\text { Output }\end{array}$ & ANFIS output & $\begin{array}{c}\text { Neural } \\
\text { Network } \\
\text { output }\end{array}$ \\
\hline 1 & $\begin{array}{l}\text { The motor in normal } \\
\text { operating condition }\end{array}$ & 0 & 0.03 & 0.1236 \\
\hline 1 & $\begin{array}{l}\text { One phase loss or line to } \\
\text { ground fault }\end{array}$ & 1 & 1.022 & 0.864 \\
\hline 2 & Line to line fault & 2 & 2.067 & 1.8234 \\
\hline 3 & $\begin{array}{l}\text { Short circuit in the stator } \\
\text { winding }\end{array}$ & 3 & 2.923 & 3.2398 \\
\hline 4 & $\begin{array}{l}\text { Short circuit in the rotor } \\
\text { winding }\end{array}$ & 4 & 4.123 & 4.383 \\
\hline
\end{tabular}

Journal of Engineering Sciences, Assiut University, Faculty of Engineering, Vol. 41, No. 4, July, 2013, E-mail address: jes@aun.edu.eg 
Mohamed Mahmoud Ismail, Predictive maintenance based on earlier fault detection on multi phase induction machines using neural network artificial intelligent techniques, pp. 1612 - 1636

\section{Table 4.}

Fault detection for five phase induction motor

\begin{tabular}{|c|c|c|c|c|}
\hline Item & Type of fault & $\begin{array}{c}\text { Expected } \\
\text { Output }\end{array}$ & ANFIS output & $\begin{array}{c}\text { Neural } \\
\text { Network } \\
\text { output }\end{array}$ \\
\hline 1 & $\begin{array}{c}\text { The motor in normal } \\
\text { operating condition }\end{array}$ & 0 & 0.0678 & 0.278 \\
\hline 1 & $\begin{array}{c}\text { One phase loss or line to } \\
\text { ground fault }\end{array}$ & 1 & 1.0987 & 0.78064 \\
\hline 2 & Line to line fault & 2 & 2.1345 & 2.2983 \\
\hline 3 & $\begin{array}{c}\text { Short circuit in the stator } \\
\text { winding }\end{array}$ & 3 & 3.223 & 2.7189 \\
\hline 4 & $\begin{array}{c}\text { Short circuit in the rotor } \\
\text { winding }\end{array}$ & 4 & 4.0145 & 4.2391 \\
\hline
\end{tabular}

\section{Table 5.}

Fault detection for six phase induction motor

\begin{tabular}{|l|l|c|c|c|}
\hline Item & \multicolumn{1}{|c|}{ Type of fault } & $\begin{array}{c}\text { Expected } \\
\text { Output }\end{array}$ & ANFIS output & $\begin{array}{c}\text { Neural } \\
\text { Network } \\
\text { output }\end{array}$ \\
\hline 1 & $\begin{array}{l}\text { The motor in normal } \\
\text { operating condition }\end{array}$ & 0 & 0.14507 & 0.36912 \\
\hline 1 & $\begin{array}{l}\text { One phase loss or line to } \\
\text { ground fault }\end{array}$ & 1 & 1.10023 & 1.12345 \\
\hline 2 & Line to line fault & 2 & 1.8345 & 2.40082 \\
\hline 3 & $\begin{array}{l}\text { Short circuit in the stator } \\
\text { winding }\end{array}$ & 3 & 3.453 & 2.9189 \\
\hline 4 & $\begin{array}{l}\text { Short circuit in the rotor } \\
\text { winding }\end{array}$ & 4 & 4.23145 & 4.1223 \\
\hline
\end{tabular}

From the simulation results, we can see that using ANFIS and neural network techniques is effective for detection any sudden faults in the multi phase induction machines during the operation as well as can be used for predictive maintenance as in case of stator and rotor winding faults because of any short circuit in the stator or rotor windings does not occurred suddenly but if the stator or rotor resistance is decreased give an impression that a short circuit may be occurred. So the ANFIS and neural network can be used for predictive maintenance for three and multi phase induction machines. Also the simulations indicate that ANFIS technique is more accurate in the results than NN technique, however, both techniques are accepted from the point of accuracy.

\section{Conclusions}

The new in this paper is by using neural network (NN) as well as ANFIS techniques for detection of the induction motor at different fault conditions taking the saturation effect in

Journal of Engineering Sciences, Assiut University, Faculty of Engineering, Vol. 41, No. 4, July, 2013, E-mail address: jes@aun.edu.eg 
Mohamed Mahmoud Ismail, Predictive maintenance based on earlier fault detection on multi phase induction machines using neural network artificial intelligent techniques, pp. 1612 - 1636

consideration. The simulations present that these methods are effective for the three and multi phase induction machines. This paper is different from the previous work that we are using NN and ANFIS controllers for detection of the supply voltage faults as well as any short circuit appears in the motor windings. The percentage of the error is accepted in both cases, while ANFIS technique gives better accuracy than NN technique. From the simulations, we find that both methods can be used for early detection of any failure start in the motor winding for predictive maintenance. Predictive maintenance is very important factor in the industrial operation to reduce the running cost.

\section{References}

[1] D.-I. Kim, I.-J. Ha, and M.-S. Ko, "Control of induction motor via feedback linearization with input-output decoupling,” Int. J. Contr., vol. 51, no. 4, pp. 863-883, 1990.

[2] Z. Krzeminski, "Nonlinear control of induction motor," in 10th IFAC World Congress, (Munich), pp. 349-354, 1987.

[3] A. Deluca and G. Ulivi, "Dynamic decoupling of voltage frequency controlled induction motors," in 8th Int. Conf. Analysis Optimiz. Syst., (Antibes), pp. 127-137, 1988.

[4] A. Deluca and G. Ulivi, "Design of exact nonlinear controller for induction motors," IEEE Trans.Automat. Contr., vol. 34, no. 12, pp. 1304-1307, 1989.

[5] J. Chiasson, "Dynamic feedback linearization control of the induction motor," IEEE Trans. Automat. Contr., vol. 38, no. 4, pp. 1588-1594, 1993.

[6] R. Marino, S. Peresada, and P. Valigi, "Adaptive input-output linearizing control of induction motors," IEEE Trans. Automat. Contr., vol. 38, no. 2, pp. 208-221, 1993.

[7] R. Marino, S. Peresada, and P. Tomei, "Global adaptive output feedback control of induction motors with uncertain rotor resistance," IEEE Trans. Automat Contr., vol. 44, no. 5, pp. 967-983, 1999.

[8] R. Marino, P. Tomein, and C. M. Verrelli, "Adaptive control for speed-sensorless induction motors with uncertain load torque and rotor resistance," Internat. Journal Adapt. Contr. and Signal Process., vol. 19, pp. 661-685, November 2005.

[9] A. Teel, R. Kadiyala, P. Kokotovic, and S. Sastry, "Indirect techniques for adaptive inputoutput linearization of nonlinear systems," Int. J. Contr., vol. 53, pp. 193-222, 1991.

[10] J. Chiasson, "A new approach to dynamic feedback linearization control of an induction motor,” IEEE Trans. Automat. Contr., vol. 43, no. 3, pp. 391-397, 1998.

[11] C. R. Sullivan and S. R. Sanders, "Models for induction machines with magnetic saturation of the main flux path," IEEE Trans. Ind. Applicat., vol. 31, no. 4, pp. 907-917, 1995.

[12] H. Hofmann, S. R. Sanders, and C. R. Sullivan, "Stator-flux-based vector control of induction machines in magnetic saturation," IEEE Trans. Ind. Applicat., vol. 33, no. 4, pp. 935-941, 1997.

[13] D. S. Kirshnen, D. W. Novotny, and T. Lipo, "On-line efficiency optimization of a variable frequency induction motor drive," IEEE Trans. Indus. App., vol. IA-20, no. 4, pp. 610616, 1985.

[14] M. Tarbouchi and H. LeHuy, "Control by exact linearization of an induction motor in field weakning regime," in IECON Proc., (Aachen, Germany), pp. 1597-1602, 1998.

[15] R. T. Novotnak, J. Chiasson, and M. Bodson, "High performance motion control of an induction motor with magnetic saturation," IEEE Trans. Contr. Syst. Techn., vol. 7, no. 3, pp. 315-327, 1999.

[16] W. Leonard, Control of Electric Drives. Berlin: Springer-Verlag, 1985. [17] E. Levi, “A unified approach to main flux saturation modeling in $\mathrm{d}-\mathrm{q}$ axis models of induction machines," IEEE Trans. Ener. Conv., vol. 10, no. 10, pp. 455-461, 1995.

[17] L. U. Gokdere, Passivity-Based Methods for Control of Induction Motors. PhD thesis, Univ. Pittsburgh, 1996.

Journal of Engineering Sciences, Assiut University, Faculty of Engineering, Vol. 41, No. 4, July, 2013,E-mail address: jes@aun.edu.eg 
Mohamed Mahmoud Ismail, Predictive maintenance based on earlier fault detection on multi phase induction machines using neural network artificial intelligent techniques, pp. 1612 - 1636

[18] P. J. Nicklasson, R. Ortega, and G. Espinosa-Perez, "Passivity-based control of a class of blondel-park transformable electric machines," IEEE Trans. Automat. Contr., vol. 42, no. 5, pp. 629-647, 1997.

[19] H. A. Abdel Fattah and K. A. Loparo, "Induction motor control system performance under magnetic saturation," in Proceedings of the American Control Conference, (San Diego, CA), pp. $1668-1672,1999$.

[20] H. A. Abdel Fattah and K. A. Loparo, "Passivity-based torque and flux tracking for induction motors with magnetic saturation," Automatica, vol. 39, pp. 2123-2130, December 2003.

[21] M.Sreedevi and P.Jeno Paul " Stator Fault Detection and diagnosis of a induction motor using neuro fuzzy logic “ Journal of Electrical and power engineering , pp 102-107,2011

[22] M.E.H. Benbouzid, "Bibliography on induction motors faults detection and diagnosis," IEEE Trans. on Energy Conversion, Vol. 14 Issue 4, pp. 1065 -1074, Dec. 1999.

[23] M.E.H. Benbouzid,, M. Vieira, and C. Theys, "Induction motors' faults detection and localisation using stator current advanced signal processing techniques," IEEE Trans. on Power Electronics, Vol. 14, No. 1. pp. 14 - 22, January 1999.

[24] S. Altug, M-Y. Chow, and J.H. Trussell, "Fuzzy inference systems implemented on neural architectures for motor fault detection and diagnosis," IEEE Tr. on Industrial Electronics, Vol. 46, No. 6, pp. 1069-1079.

[25] S.L. Ho and K.M. Lau, "Detection of faults in induction motors using artificial neural networks. Electrical machines and drives," IEEE Conf. publication No. 412. 11-13 September 1995.

[26] N. Arthur, and J. Penman, "Induction machine condition monitoring with higher order spectra," IEEE Trans. on Industrial Electronics, Vol. 47, No. 5, pp. 1031-1041,Oct. 2000.

[27] S. Moreau, J.C. Trigeassou, G. Champenois and J.P.Gaubert, "Diagnosis of Induction machines: A procedure for electrical fault detection and localization," IEEE Int.Symp. on Diagnostics for Electrical Machines, Power Electronics and Drives, Sept. 1-3 1999, Gijon Spain, pp.225-230.

[28] Z. Ye and B. Wu, "A Review on Induction Motor Online Fault Diagnosis," Int. Power Electronics and Motion Control Conf. p. 1353- 1358. Vol. 3, 15-18 Aug. 2000.

[29] J. Chen and R. Patton, Robust Model-Based Fault Diagnosis For Dynamic Systems, Kluwer Academic Publishers, 1999.

[30] M-Y. Chow, Methodologies of Using Neural Network and Fuzzy Logic Technologies for Motor Incipient Fault Detection, World Scientific Publishing, Singapore, 1997.

[31] F. Filippetti, G. Franceschini, and C. Tassoni, "Neural networks aided on-line diagnostics of induction motor rotor faults," IEEE Trans. on Industrial Applications, Vol. 31,No. 4, pp. 892-899, July/August 1995.

[32] S. Haykin, Neural Networks: A Comprehensive Foundation, Macmillan Publishing Co., Englewood Cliffs, NJ, 1994.

[33] R. Isermann, "Process Fault Detection Based on Modelling and Estimation Methods - A Survey," Automatica Vol. 20, No. 4, pp. 387-404, 1984.

[34] M. Norgaard, "Neural Network Based System Identification Toolbox," Tech. Report. 00E-891, Dept. of Automation, Technical University of Denmark, 2000.

[35] T. Wildi, Electrical Machines, Drives and Power Systems, Prentice Hall, 3rd ed., Englewood Cliffs, NJ, 1996.

[36] Z. Ye and B. Wu, and N. Zargari, "Online Mechanical Fault Diagnosis of Induction Motor by Wavelet Artificial Neural Network Using Stator Current," IEEE IECON 2000, Vol. 2, pp. $1183-1188,22-28$ Oct. 2000.

[37] Z. Ye and B. Wu, "A review on induction motor online fault diagnosis," Proc. of Power Electronics and Motion Control Conference PIEMC, pp. 1353 -1358, 2000.

[38] A.G. Parlos, K. Kim, "Model-Based Incipient Fault Diagnosis - Multi-Step NeuroPredictors and Multiresolution Signal Processing," Proc. Int. Joint Conf. on Neural Networks, IJCNN 02, Vol. 1, pp. 317-322, 12-17 May 2002.

Journal of Engineering Sciences, Assiut University, Faculty of Engineering, Vol. 41, No. 4, July, 2013,E-mail address: jes@aun.edu.eg 
Mohamed Mahmoud Ismail, Predictive maintenance based on earlier fault detection on multi phase induction machines using neural network artificial intelligent techniques, pp. 1612 - 1636

[39] S. M, "Industrial applications of fuzzy control," North-Holland, Amsterdam, 1985.

[40] M. II.R, "Fuzzy logic technology and applications," IEEE Press, Piscataway,, 1994.

[41] M. Gupta and S. N., "Intelligent control systems," Theory and Applications, IEEE Press, Piscataway, NJ,, 1996.

[42] K. B., "Fuzzy engineering," Prentice Hall, Upper Saddle River, NJ, 1997.

[43] R. A, "Applied research in fuzzy technology," Kluwer Academic Publishers, Boston, 1994.

[44] K. A. and Gupta, "Introduction to fuzzy arithmetic theory and applications," Van Nostrand Reinhold, 1985.

[45] T. R. Nguyen H, Sugeno M and Y. R, “Theoretical aspects of fuzzy control," John Wiley and Sons, 1995.

[46] Kowalski, C.T. and T. Orlowska-Kowalska, Neural networks application for induction motor faults diagnosis. Math. Comput. Simul., 2003. 63(3-5): p. 435-448.

[47] Specht, D.F., Probabilistic neural networks. Neural Networks, 1990. 3(1): p. 109-118.

[48] Joarder Kamruzzaman, R.B.a.R.S., Artificial neural networks in finance and manufacturing.2006. Computing and Engineering Researchers' Conference, University of Huddersfield, Dec 2010

[49] O. Hasan (2004) Fault detection, diagnosis and prognosis of rolling element bearings: Frequency domain methods and hidden Markov modeling. Case Western Reserve University, Ph.D Thesis

[50] Abd Hamid, M.K. (2003). Multiple Faults Detection Using Artificial Neural Network. Universiti Teknologi Malaysia: Master's Thesis.

\title{
الصيانة الوقائية للمحركات متعددة الأوجه اعتماداً على المعرفة المبكرة للأعطال

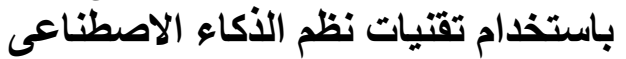

\begin{abstract}
الملخص العربى
مجال المحركات متعدد المر احل على وجه الخصوص قد شهدت نمو ا كبير ا منذ بداية هذا القرن. وقد أجريت

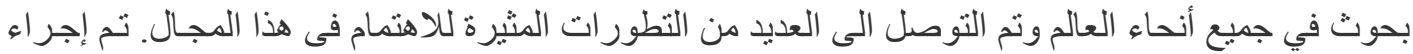

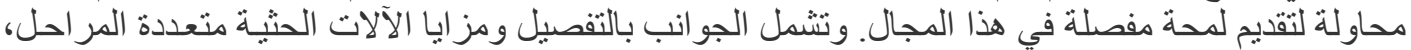

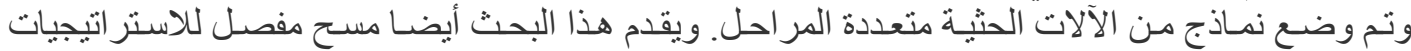

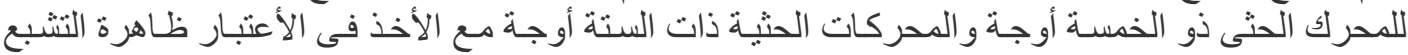

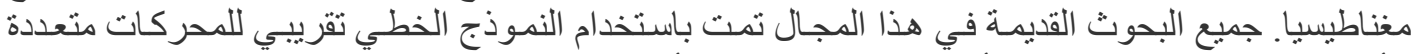

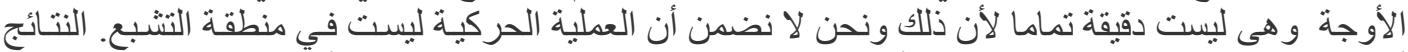

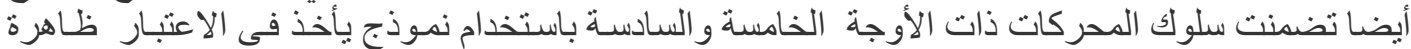

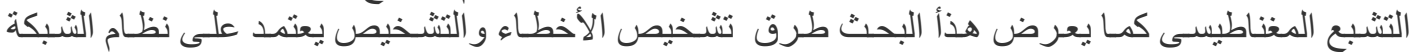
العصبية الأصطناعية (ANN) وحالة الأنظمة التكيفية العصبية غامض الاستدلال (ANFIS) و و هو

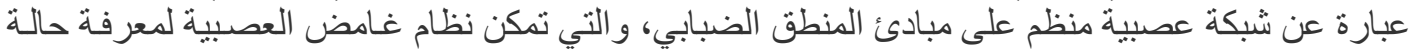

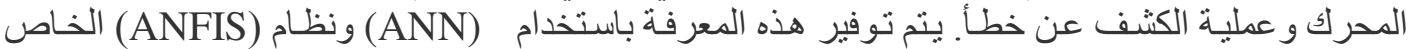

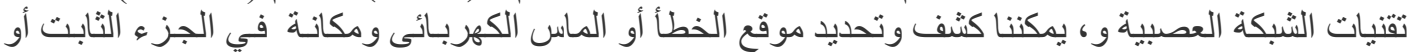

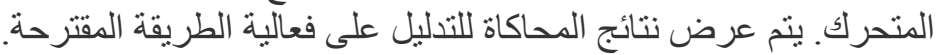

Journal of Engineering Sciences, Assiut University, Faculty of Engineering, Vol. 41, No. 4, July, 2013,E-mail address: jes@aun.edu.eg 